\title{
Minima of interannual sea-level variability in the Indian Ocean
}

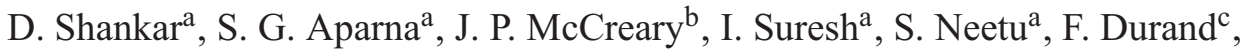 \\ S. S. C. Shenoi ${ }^{\mathrm{a}}$, M. A. Al Saafania, \\ ${ }^{a}$ National Institute of Oceanography, Dona Paula, Goa 403 004, India. \\ ${ }^{b}$ SOEST, University of Hawaii, Honolulu, Hawaii, USA. \\ 'IRD, LEGOS, UMR5566 CNRS-CNES-IRD-UPS, 14 Avenue Edouard Belin, 31400 Toulouse, \\ France. \\ ${ }^{d}$ Department of Earth and Environmental Sciences, Faculty of Science Sana'a University, Yemen.
}

\begin{abstract}
Wavelet analysis of altimeter sea level in the Indian Ocean shows regions of high variability (maxima) and low variability (minima) at all time scales. At interannual time scales, i.e., at periods of 17 months or more, minima are seen at several places: in the central equatorial Indian Ocean; in the Arabian Sea along the south and west coasts of India and Sri Lanka, along the northern boundary, in the Gulf of Aden, and in patches along the coast of Oman; and in the Bay of Bengal along the east coasts of Sri Lanka and India south of $\sim 10^{\circ} \mathrm{N}$, and in the southern bay east of the Sri Lanka thermal dome. We investigate the cause of these interannual minima using a linear, continuously stratified numerical model, which is able to simulate the observed minima. We separate the forcing into a set of processes: direct forcing by winds in the interior ocean, forcing by winds blowing along continental boundaries, and forcing by Rossby waves generated by the reflection of equatorial Kelvin waves at the eastern boundary. At interannual periods, minima (maxima) of interannual variability occur where the direct wind forcing and reflected Rossby waves interfere destructively (constructively). At interannual pe-
\end{abstract}


riods within the tropics, the adjustment time scale of the system is less than that of the forcing, leading to a quasi-steady balance, a property that distinguishes the interannual minima from those at annual and semiannual time scales. Idealised solutions show that the presence of India forces the minimum along the Indian west coast, and that it extends around the perimeter of the Arabian Sea into the Gulf of Aden. 


\section{Introduction}

\subsection{Background}

During the past decade, there has been remarkable progress in observing and understanding interannual variability in the Indian Ocean. This progress was triggered by advances in satellite technology and the occurrence of an intense Indian Ocean Dipole/Zonal Mode (IODZM; also called the Indian Ocean Dipole or Indian Ocean Zonal Mode) during 1997, a climatic event associated with anomalous easterlies along the equator and both cool sea-surface temperature (SST) and low sea level in the eastern equatorial Indian Ocean (EEIO) (Murtugudde et al., 1998; Saji et al., 1999; Webster et al., 1999; Murtugudde and Busalacchi, 1999; Murtugudde et al., 2000). Since that time, the impacts of both IODZM and El Niño and the Southern Oscillation (ENSO) on Indian Ocean SST and circulation have been studied extensively, and there is evidence that interannual SST anomalies in the Indian Ocean feedback to affect winds and rainfall locally and remotely. See Yamagata et al. (2004), Annamalai and Murtugudde (2004), Chang et al. (2006), and Schott et al. (2009) for reviews of this progress.

Sea-level variability has been particularly useful for describing and understanding ENSO, IODZM, and other phenomena because of the information it provides about ocean dynamics. Sakova et al. (2006) used TOPEX/Poseidon data to show the existence of large sea-level signals in five frequency bands (semiannual, annual, 18-20 months, 3 years, and 4-6 years), the bands "being separated by substantial spectral gaps." Figure 1 shows the variability in the semiannual, annual, 17-20 months, and 3-year bands. (The 4-6-year band is not resolved well in the short altimeter record.) Interestingly, regions of both high and low variability are evident in all the panels. Although the magnitude of variability varies through 
the interannual period range from 17 months to over 3 years, the spatial patterns for these interannual bands are similar (Figure 1; see also Figure 5 of Sakova et al. (2006)). The structures of these high- and low-variability regions in the 17-20month and 3-year bands, however, differ markedly from those for the annual and semiannual periods, pointing toward the importance of different processes acting at the three time scales: interannual, annual, and semiannual.

Baroclinic waves are more apparent in the north Indian Ocean than they are in the other oceans owing to its tropical location, its small size, and the seasonal forcing by the monsoon winds. The presence of baroclinic waves, which have received considerable attention in the literature (see, for example, the review by Schott and McCreary, 2001) implies that changes in sea level can be forced at a given location by winds blowing elsewhere earlier in the season. This phenomenon, called remote forcing, "merges the equatorial Indian Ocean, the Arabian Sea, and the Bay of Bengal into a single dynamical entity" (Shankar et al., 2002). These waves are evident at time scales from intraseasonal to interannual.

One of the first descriptions of the basin-scale, baroclinic waves in the IO, based on the relatively coarse Geosat data, revealed the presence of annual Rossby waves outside the equatorial waveguide in both hemispheres (Perigaud and Delecluse, 1992a). Such westward-propagating Rossby waves were subsequently observed in altimeter sea level, radiating from the eastern boundaries of the Bay of Bengal (Perigaud and Delecluse, 1993; Vinayachandran et al., 1999) and the Arabian Sea (Shankar and Shetye, 1997; Brandt et al., 2002; Shankar et al., 2004; AlSaafani et al., 2007), and in the south Indian Ocean (Perigaud and Delecluse, 1993; Fu and Smith, 1996). The existence of annual Rossby waves has since been confirmed even in expendable bathythermograph (XBT) data (Masumoto and Meyers, 1998) 
and in a climatology (Levitus, 1982) of hydrographic data (Unnikrishnan et al., 1997). Such Rossby waves, as well as coastal and equatorial Kelvin waves, also appear prominently in model simulations (Lighthill, 1969; McCreary et al., 1993; Schott and McCreary, 2001; Shankar et al., 2002).

In the equatorial waveguide, the semiannual signal is also strong in the eastern and western ocean (Knox, 1976; Luyten and Roemmich, 1982; Reverdin, 1987), there being a minimum-variability region in between (Figure 1).

Model studies show that this strong semiannual signal is due to constructive interference of incident (directly forced by the wind) and reflected waves (Blanc and Boulanger, 2001) for the second baroclinic mode (Jensen, 1993; Clarke and Liu, 1993; Han et al., 1999). Also playing a role in enhancing the semiannual signal are the different spatial structures of the annual and semiannual winds, resonance with the semiannual wind, and shear flow in the mixed layer of the EEIO (Han et al., 1999).

At interannual time scales, Rossby-wave propagation in the tropical south Indian Ocean is evident even in Geosat data (Perigaud and Delecluse, 1992b). These interannual Rossby waves are prominent in altimeter (Fu and Smith, 1996) and XBT (Masumoto and Meyers, 1998) data and in model simulations (Perigaud and Delecluse, 1992b; Masumoto and Meyers, 1998). Particularly prominent is the interannual Rossby wave in the south Indian Ocean (Masumoto and Meyers, 1998) associated with ENSO (e. g. Schott et al., 2009).

\subsection{Present research}

In this paper, we investigate the processes that lead to an interannual sealevel pattern like that in the top panels of Figure 1. Although the pattern involves both maxima and minima of variability, we focus on the latter. The maxima have 
received considerable attention in the literature. An example is the maximum in the EEIO, which is associated with IODZM events (see, for example, reviews by Yamagata et al., 2004; Annamalai and Murtugudde, 2004; Chang et al., 2006; Schott et al., 2009); this maximum is also prominent in spatial maps of 18-20month and 3-year variability (Sakova et al., 2006). The minima, however, are surprising, given the prevalence of remotely forced waves that can spread signals throughout the basin. They are therefore more indicative of basic physics than are the maxima.

Our approach is to identify prominent features of the interannual response in sea-level observations (Section 2), to assess the contributions of directly-forced and boundary-wave responses using a numerical ocean model (Section 3), and to illustrate basic dynamics by obtaining solutions to a simplified version of the model that allows for an analytic solution (Section 4). Section 5 concludes the paper.

We emphasize here that the term "interannual variability" designates the variability that remains after a time series is low-pass filtered to retain frequencies lower than the annual. Thus, short-term interannual (ENSO, IODZM) events, prominent aspects of which (e.g., SST anomalies) typically last less than a year, appear as low-frequency (2-6 year) signals in our analyses, a potential confusion of time scales. On the other hand, sea-level variations associated with such events involve the off-equatorial propagation of Rossby waves and so do adjust at interannual time scales. Hence, in summary, we consider interannual variability in frequency space rather than considering it to be a result of events that occur every few years.

We find that minima, i. e., regions of low interannual variability, occur pri- 
marily from the destructive interference between the directly-forced response and boundary-reflected waves. In addition, their horizontal structure is similar at periods of 17 months or longer, a property that can be understood in terms of simple physics: Essentially, these periods are longer than the adjustment time of the tropical Indian Ocean, so that the ocean is nearly adjusted to a quasi-steady state.

\section{Observational analyses}

\subsection{Data}

\subsubsection{AVISO sea level}

Our primary data set is the gridded sea-level product from AVISO (AVISO, 1996, hereafter referred to as AVISO) for the period 1993-2004, from which sealevel anomalies (SLAs) are computed relative to the 7-year mean from 19931999. The AVISO product merges data from several altimeters to produce a weekly gridded field on a $0.33^{\circ} \times 0.33^{\circ}$ Mercator projection grid (Ducet et al., 2000), the merged data set having smaller mapping errors and better spatial coverage than a data set based on any one satellite (Ducet et al., 2000; Volkov, 2005). Comparison with the recently processed MAP (Margins Altimetry Project) data (Vignudelli et al., 2000) shows that the gridded data product has problems near coasts, but it is accurate offshore (Durand et al., 2008, 2009).

\subsubsection{Spatial and temporal sampling}

To facilitate comparison with the numerical simulations reported in Section 3, we used the regridding tool in Ferret (Hankin et al., 2006) to remap the AVISO SLA onto the model's $0.5^{\circ} \times 0.5^{\circ}$ grid. We considered sampling intervals of both one week and one month. As may be expected (DeMoortel et al., 2004), the

magnitudes of the wavelet transforms (discussed next) based on the two sampling 
intervals differ somewhat, but their spatial patterns are essentially the same. In the rest of this paper, then, we report analyses of monthly records.

\subsubsection{Wavelet analysis}

To show how spatial patterns of the response vary with frequency, we subjected the data to a wavelet analysis using a Morlet wavelet as the basis function. The advantage of a wavelet transform over a traditional Fast Fourier Transform (FFT) analysis is that it also provides the variation of structures with time. Given the considerable interannual variability even within the limited duration of the altimeter record (see, for example, the wavelet spectrum of the $20^{\circ} \mathrm{C}$ isotherm in Figure 2 of Sakova et al. (2006)), the wavelet transform yields more information than is available from an FFT analysis. The maps of wavelet power in Figure 1 are averaged over 1993-2004 for the semiannual, annual, 17-20-month, and 3year period bands, defined by averages over 5.8-6.9 months, 9.8-13.9 months, 16.5-19.7 months, and 33.0-39.3 months, respectively. These maps show the variability of sea level at the given periods.

\subsection{Results}

\subsubsection{Regions of high variability}

Consistent with the spectral-density plots of Sakova et al. (2006) (their Figure 5), wavelet power for the 17-20-months and 3-year bands (top panels of Fig-

ure 1) shows maxima in the tropical south Indian Ocean between $5-10^{\circ} \mathrm{S}$, in the eastern equatorial Indian Ocean off Sumatra and Java, and in the Somali-Current region. There are weaker maxima in the northwestern $\left(\sim 15^{\circ} \mathrm{N}\right)$ and southwestern $\left(\sim 8^{\circ} \mathrm{N}\right)$ Bay of Bengal, both regions being thermal domes where the thermocline is shallow (Shetye et al., 1996; Vinayachandran and Yamagata, 1998). 


\subsubsection{Regions of low variability}

The most prominent minimum occurs in the central equatorial Indian Ocean (CEIO) between the relative maxima in the EEIO and western equatorial Indian Ocean (WEIO; top panels of Figure 1). Extending southeastward from this CEIO minimum is a minimum "tongue" separating the maxima off Sumatra and the tropical south Indian Ocean between $5-10^{\circ} \mathrm{S}$. A longitude-period section along the equator shows that minima occur in the CEIO at all periods greater than the annual (top panel of Figure 2), from a period around 17 months to over 3 years (the highest period resolved by the data set).

The CEIO minimum is contiguous to the minima south of Sri Lanka and along the Indian west coast. The latter region broadens to the north, where it spreads almost halfway across the northern Arabian Sea and extends along the northern boundary of the Arabian Sea. There are also minima in the Gulf of Aden and along the Somali coast; they are separated from each other and from the minimum in the northern Arabian Sea by maxima that occur off Oman and northern Somalia. These maxima occur in regions of high eddy activity, two examples being the Great Whirl and the Socotra Eddy (Schott and McCreary, 2001), and the high interannual variability of the eddy field accounts for the distinct maxima seen in the wavelet analysis (Figure 1).

The minimum south of Sri Lanka also extends along the east coast of India into the Bay of Bengal to about $13^{\circ} \mathrm{N}$. To its east is a relative maximum in the regime of the Sri Lanka dome (Vinayachandran and Yamagata, 1998); farther east is a broad minimum that spreads across most of the southern Bay of Bengal. To the north of this southern-bay minimum is a maximum that covers much of the central bay. The minimum in the southern bay, however, extends into the northcentral bay 
as an anticlockwise semicircular arc that bounds the central-bay maximum on its east and north. Finally, along the perimeter of the northern Bay of Bengal, there is a maximum hugging the coasts of Myanmar (Burma), Bangladesh, and India north of about $13^{\circ} \mathrm{N}$.

\subsubsection{Time series}

We filtered the sea-level data with a low-pass filter, using a third-order Butterworth filter with a cutoff period of 18 months. Figure 3 plots the resulting time series at 8 locations, indicated by numbers in Figure 1, in the basin. In regions of maximum variability (locations 2, 5, and 7), sea level has a higher range than at minimum locations (locations 1, 3, 4, 6, and 8), but the range was low even in some maximum locations during some years. For example, in the maximum off Somalia (location 2) and in the thermal domes (location 5), the range decreased after 2000. In contrast, in regions of variability minima, the range of sea level was low throughout the record. That the variability is low at all times in the minimum locations is the essential difference between them and the maximum locations. This difference is clearly seen in a wavelet analysis of the altimeter sea level (Figure 4) at these locations: At all periods greater than the annual, variability is low at minimum locations throughout the record, although there is a variation in the wavelet power with both period and time. In maximum locations, wavelet power shows higher temporal variation.

\subsubsection{Summary}

Despite noise in the form of patches of high and low interannual variability, regions of minimal variability are as distinct as those of maximal variability reported earlier (Sakova et al., 2006). Although the altimeter record is too short to determine if similar minima exist at longer periods, their existence at all resolved 
periodicities greater than the annual, their persistence throughout the duration of the record (Figures 3 and 4), and their spatial connectedness suggests that the phenomenon is an intrinsic feature of all Indian-Ocean sea-level variability at sufficiently long periods. In the rest of this paper, we seek to determine the cause of these minima.

\section{Numerical solutions}

In this section, we first describe our ocean model, also providing justifications for its linearity and that it is only wind-driven (Section 3.1). Then, we report our main run, comparing it with observations (Section 3.2), and commenting on the model's limitations (Section 3.3). We then separate our main run into several parts (process solutions), noting that only two processes are important at periods greater than the annual, and that minima occur when these two processes tend to interfere destructively (Section 3.4). We conclude with a discussion of the model results at periods higher than those resolved by the altimeter data (Section 3.5).

\subsection{Ocean model}

A useful tool for understanding the wind-driven oceanic response is the linear, continuously stratified (LCS) model described next. It has already been used to investigate a variety of Indian-Ocean phenomena. For example, it was used to study the dynamics of the East India Coastal Current (EICC) (Shankar et al., 1996; McCreary et al., 1996), the West India Coastal Current (WICC) (Shankar and Shetye, 1997; Nethery and Shankar, 2007), and the impact of the Indonesian Throughflow on Indian Ocean circulations (McCreary et al., 1986, 2007). Here, we present a brief overview of the model. Additional details can be found elsewhere (McCreary, 1980, 1981; Shankar et al., 1996; McCreary et al., 1996). The 
model is limited in several ways, namely, it is only wind-forced, is linear, and has a flat bottom. We begin with a discussion of why we feel these limitations are not serious problems.

\subsubsection{Justification}

Non-tidal sea-level variations can result from atmospheric pressure, buoyancy fluxes, and wind forcing (Patullo et al., 1955). At interannual time scales, variations in atmospheric pressure can be ignored (see Section 6.1 in Shankar (1998), downloadable from http://hdl.handle.net/2264/24). Han and Webster (2002) considered the impact of buoyancy fluxes on interannual sea level in the Bay of Ben-

gal, concluding that variability of river discharge has a negligible impact along the east coast of India, but that variability of precipitation over the Bay of Bengal is important. When the freshwater fluxes are high (low), steric sea level will rise (fall), leading to high variability in regions affected by (variability in) freshwater fluxes. Hence, freshwater fluxes are more relevant for sea-level-variability maxima. This effect, however, can be expected to be limited to the regions of high precipitation and to regions where low-salinity water is advected (Han and Webster, 2002; Shankar and Shetye, 1999, 2001; Shankar, 2000). Hence, in order to explain the existence of the interannual-sea-level-variability minima in the CEIO and along the boundaries of the Arabian Sea and Bay of Bengal, we can restrict our attention to the effect of wind forcing.

As noted by Shankar and Shetye (1997) and Shankar et al. (2002), much of the response in the Indian Ocean can be understood in terms of linear dynamics, significant nonlinearities being restricted to the Somali-Current regime. Another significant nonlinearity is related to regions of strong upwelling, one of them lying off Somalia and the other off Oman. The simulations of Shankar and Shetye 
(1997) and Shankar et al. (2002) show, however, that the upwelling off the Indian west coast is explicable by linear wave theory.

To represent solutions as expansions in vertical normal modes (see below), the LCS model must have a flat bottom, thereby excluding continental-shelf processes. As can be seen from the wavelet analysis in Figure 1, however, the minima exist on the shelf, off the shelf, and in the open ocean, implying the lack of relevance of shelf physics for their existence.

\subsubsection{Equations}

The equations of motion of the LCS model are linearized about a state of rest, with a background Brünt-Väisälä frequency, $N_{b}(z)$, given by the profile of Moore and McCreary (1990). There is vertical mixing with coefficients of the

form $v=A / N_{b}^{2}$ and $A=1.3 \times 10^{-4} \mathrm{~cm}^{2} / \mathrm{s}$, wind is introduced into the ocean as a body force of the form $Z(z)=\theta(z+H) / H$, where $H=50 \mathrm{~m}$, and the ocean bottom is assumed flat with a depth $D=4000 \mathrm{~m}$.

Let $q$ be either $u, v$, or $p$. Then, $q$ can be written

$$
q(x, y, z, t)=\sum_{n=1}^{N} q_{n}(x, y, t) \psi_{n}(z),
$$

where the set of functions $\psi_{n}(z)$ are the vertical (barotropic and baroclinic) modes of the system that satisfy the eigenfunction equation,

$$
\left(\frac{\psi_{n z}}{N_{b}^{2}}\right)_{z}=-\frac{1}{c_{n}^{2}} \psi_{n}
$$

subject to the boundary conditions $\psi_{n z}(0)=\psi_{n z}(-D)=0$ and normalized so that $\psi_{n}(0)=1$. The eigenvalues $c_{n}$ are the Kelvin-wave speeds for mode $n$. The summation in (1) should extend to $\infty$, but in practice it must be truncated at a finite value $N$. In the present study, we use choose $N=10$, and most of the 
response is captured by the first two modes. The summation begins at $n=1$, thereby neglecting the barotropic $(n=0)$ response; as in McCreary et al. (1996), the barotropic impact on sea level is weak in comparison to the baroclinic response in our wind-driven solutions.

The resulting set of equations for the expansion coefficients is

$$
\begin{gathered}
u_{n t}-f v_{n}+\frac{1}{\bar{\rho}} p_{n x}=F_{n}-\left(\frac{A}{c_{n}^{2}}\right) u_{n}+v_{h} \nabla^{2} u_{n}-\delta u_{n}, \\
v_{n t}+f u_{n}+\frac{1}{\bar{\rho}} p_{n y}=G_{n}-\left(\frac{A}{c_{n}^{2}}\right) v_{n}+v_{h} \nabla^{2} v_{n}, \\
\frac{1}{c_{n}^{2}} p_{n t}+u_{n x}+v_{n y}=-\left(\frac{A}{c_{n}^{2}}\right) p_{n}-\frac{\delta}{c_{n}^{2}} p_{n},
\end{gathered}
$$

where $F_{n}=\tau^{x} Z_{n} / \mathcal{H}_{n}, G_{n}=\tau^{y} Z_{n} / \mathcal{H}_{n}, \mathcal{H}_{n}=\int_{-D}^{0} \psi_{n}^{2} d z$, and $Z_{n}=\int_{-D}^{0} Z(z) \psi_{n}(z) d z$. The coefficient $Z_{n} / \mathcal{H}_{n}$ determines how strongly mode $n$ is coupled to the wind. The horizontal mixing coefficient $v_{h}=5 \times 10^{7} \mathrm{~cm}^{2} \mathrm{~s}^{-1}$, which is large enough to ensure numerical stability (McCreary et al., 1996). Some test solutions include a damper $\delta(x, y)$ in the EEIO $\left(x>92.75^{\circ} \mathrm{E},-7.5^{\circ} \mathrm{S}<y<7.5^{\circ} \mathrm{N}\right)$, which absorbs incoming equatorial Kelvin waves as well as the Rossby waves that reflect from the eastern boundary (McCreary et al., 1996). Following McCreary et al. (1996), $\delta$ has a maximum value of $c_{n} /(1.5 \Delta x)$ (where $\Delta x$ is the zonal grid spacing) in this region, and decreases linearly to zero within $5^{\circ}$ of its western edge and within $2^{\circ}$ of its northern and southern edges. The advantage of equations (3) is that the original, three-dimensional $(x, y$, and $z)$ set of equations are reduced to two dimensions ( $x$ and $y)$.

\subsubsection{Basin geometry, boundary conditions, and forcing}

Solutions are found for a realistic basin geometry north of $29^{\circ} \mathrm{S}$, with continental boundaries lying roughly along the $200 \mathrm{~m}$ isobath. The grid used is Arakawa-C 
with a uniform spacing of $0.5^{\circ}$. The basin shape north of $10^{\circ} \mathrm{S}$ is shown in Figure 5, and the entire basin is provided in McCreary et al. (1993). For most of our solutions, closed, no-slip conditions

$$
u_{n}=v_{n}=0
$$

are applied along continental boundaries, the exceptions being two of our process solutions that use alternate conditions (Equations (5) below). With these closed boundary conditions, the Indonesian passages are always closed so that there is no Indonesian Throughflow in any of our solutions.

The model ocean is forced by monthly winds from the NCEP/NCAR (National Centers for Environmental Prediction/National Center for Atmospheric Research) reanalyses (Kalnay et al., 1996). It is spun up from a state of rest starting on 1 January 1948, and model output from 1993-2004 is used for comparison with the altimeter sea level.

\subsection{Main run}

Our main run (Solution MR) is the solution obtained using boundary conditions (4) along all continental boundaries and without the equatorial damper, i. e., $\delta(x, y)=0$. As for the altimeter data, we carried out a wavelet analysis of the model sea level to obtain time-averaged plots of wavelet power. Figure 2 (bottom panel) shows wavelet power along the equator as a function of period, and Figure 5 (top left panel) presents the spatial map of wavelet power at the 3-year period; the map for the 17-20-month period is similar to that for the 3-year period.

\subsubsection{Maps of interannual wavelet power}

Solution MR (top left panel of Figure 5) reproduces all the prominent maxima and minima in the altimeter data at the 3-year period (Figure 1), the most obvious 
model/data difference being the smoothness of the solution, which is expected because the model is linear. The solution simulates the observed minima in the CEIO, along the eastern and northern boundaries of the Arabian Sea, in the Gulf of Aden, along the southeast coast of India and Sri Lanka, and in the southern Bay of Bengal. In addition, it also simulates a narrow minimum along the Omani coast, not apparent in the observations. Finally, note that there is a maximum in the region of the thermal domes in the southwestern Bay of Bengal, as in the altimeter sea level; also, as in the observations, the maximum in the regime of the Sri Lanka dome in the southwestern bay separates the coastal minimum and the open-ocean minimum in the southern bay.

\subsubsection{Time series}

As for the altimeter sea level, we filter model sea level with a low-pass thirdorder Butterworth filter with a cutoff period of 18 months. In regions not influenced by river discharge or high rainfall (like the northern Bay of Bengal: not shown), the model sub-annual variability is similar to that observed (Figure 3).

\subsection{Model limitations}

\subsubsection{Minimum tongue southeast of the CEIO}

The altimeter data show a striking minimum tongue extending southeastward from the CEIO (Figure 1), but the model solution merely hints at its existence, the tongue being very weak in the model and its connection to the CEIO not as evident (Figure 5). A detailed analysis of this model lacuna is beyond the scope of our paper, but three possible causes come to mind. First, the region south of the equator is the regime of the South Equatorial Counter Current (SECC) (see, for example, Schott and McCreary, 2001), which does not reverse with season. The SECC flows eastward, opposing the westward propagating Rossby wave. Non- 
linear interaction between the current and the wave, a process not included in the LCS model, may interfere with the Rossby wave. Second, the model has a closed eastern boundary and therefore does not include the impact of the Indonesian Throughflow; the consequences of this boundary forcing are unclear. Third, the forcing used is the winds from the NCEP/NCAR reanalysis; it is possible that the forcing is inaccurate.

\subsubsection{Coast of Oman}

The minimum along the northern boundary of the Arabian Sea extends counterclockwise along the coast of Oman (Figure 5). In the observations, however, there is no such continuous minimum along the Omani coast, the minima there appearing instead as distinct patches (Figure 1). The observations conducted off the Omani coast during the US JGOFS (Joint Global Ocean Flux Study) program showed that the offshore flow occurs in squirts and jets at a few capes like Ras al Hadd, where the Ras al Hadd Jet (Böhm et al., 1999) veers off the coast, transporting the cool, upwelled waters into the interior of the basin. Minima occur in the vicinity of these capes, being separated by relative maxima; the variability, however, is generally weaker along the Omani coast than farther offshore or southward off Somalia (Figure 1). This difference is to be expected because the model is linear and jets like the Ras al Hadd Jet are nonlinear phenomena (see the discussion in Section 4.5 in Schott and McCreary, 2001). Notwithstanding this difference, it is evident that the interannual variability of even these nonlinear jets is connected to, and determined by, that of the linear western boundary current of whose instability they are a manifestation. 


\subsubsection{Freshwater flux into northern bay}

The model solution (Figure 5) reproduces the maximum observed along the perimeter of the northern bay, counterclockwise from the east coast of Myanmar to about $13^{\circ} \mathrm{N}$ along the Indian east coast (Figure 1). This coastally trapped maximum, which implies a relative minimum offshore in the northcentral bay (Figures 1 and 5), is due to the counterclockwise propagation of Kelvin waves along the perimeter of the bay (Potemra et al., 1991; Yu et al., 1991). Nevertheless, though the wind-forced model seems to explain the existence of the maximum along the perimeter of the northern bay, we cannot rule out the possible role of freshwater flux in the region. Zonal winds over the equatorial Indian Ocean (Clarke and Liu, 1994) and Ekman pumping in the interior bay (Han and Webster, 2002) have been invoked to explain the interannual variability observed in tide-gauge sea level along the Indian east coast. A different hypothesis was proposed by Shankar and Shetye (1999), who found a strong correlation between rainfall over India and sea-level variability along the Indian west coast on interannual and interdecadal time scales: Shankar and Shetye (1999) linked the lowfrequency variability of sea level to the rainfall over India, with the large-scale coastal currents and the cross-shore gradient of salinity playing an intermediate role. Though the numerical simulations of Han and Webster (2002) suggest that interannual variability in river influx is not as important as interannual variability of winds for the sea level along the Indian east coast, Han and Webster (2002) did find that interannual variability in rainfall over the Bay of Bengal is an important cause of the interannual variability of sea level. The impact of freshwater flux, whose major source due to rivers lies in the northern bay (Shetye, 1993) and ma-

jor source due to rainfall lies in the northeastern bay (Xie and Arkin, 1999), is felt 
primarily in the regions near the source and in the regions to which this freshwater is advected. One major pathway for advection of freshwater from the northern bay is the east coast of India (Wyrtki, 1971; Shetye et al., 1996; Shenoi et al., 1999; Han et al., 2001; Durand et al., 2007; Kurian and Vinayachandran, 2007) and another pathway is along the west coast of Myanmar (Jensen, 2003). These, the northern, northeastern, and northwestern boundaries of the bay, are precisely the regions in which the maximum occurs, implying that both wind forcing and freshwater flux may be important causes of this maximum (and therefore indirectly of the relative minimum to its south in the northcentral bay). Indeed, that this maximum is stronger on the shelf of this region than on the continental slope (Figure 1) suggests an important role for freshwater flux.

\subsection{Process solutions}

The above limitations notwithstanding, the model solution is in remarkable agreement with the observations. Therefore, because the model is linear, it is possible to separate the total response into a set of process solutions, each driven by a different forcing mechanism. As we shall see, sea-level minima can then be generated by destructive interference between two or more of the process solutions.

\subsubsection{Directly-forced and boundary-wave responses}

We split the total response into contributions from three sources: 1) direct forcing by winds in the interior ocean; 2) forcing by coastal winds blowing along continental boundaries; and 3) Rossby waves generated by the reflection of equatorially trapped Kelvin waves at the Sumatra coast. Similar separations have been carried out earlier for the Bay of Bengal (Shankar et al., 1996; McCreary et al., 1996) and for the monsoon currents (Shankar et al., 2002). 
Figures 6 and 7 illustrates the two components of the wind forcing, providing plots of wavelet power along basin boundaries (process 2) and in the ocean interior (process 1), respectively. Figure 6 provides a distance-period plot of wavelet power for zonal winds along the equator and the alongshore component of the winds along the continental boundary of the northern Indian Ocean. At the annual period, power stands out in the WEIO and CEIO and almost the entire boundary of the north Indian Ocean. In contrast, at the semiannual period, the wind field is strong only in the CEIO, and the coastal winds are weak except off Oman in the regime of the Findlater Jet (Findlater, 1969). At interannual periods $(\sim 2-$ 5 years), the forcing is associated primarily with ENSO and IODZM, consisting of easterlies along the equator and southeasterlies in the southeastern tropical Indian Ocean. Interannual forcing at periods resolved in the altimeter observations ( $\leq 3$ years) is strong only in the CEIO $\left(68-96^{\circ} \mathrm{E}, 10^{\circ} \mathrm{S}-8^{\circ} \mathrm{N}\right)$.

Figure 7 plots the Ekman-pumping velocity, $w_{e k}=(1 / \bar{\rho}) \operatorname{curl}(\tau / f)$, for the 3 -year period. Ekman pumping is strong at the 3-year period, and much of it is associated with the meridional weakening of the equatorial easterlies away from the equator. Such interannual variability in Ekman pumping during IODZM and ENSO events has been discussed by several authors (Ashok et al., 2004; Yu et al., 2005; Rao and Behera, 2005); see Schott et al. (2009) for a recent review.

\subsubsection{Methodology}

To separate the contributions from each of these forcings, we obtain three test solutions (TS). The first solution (Solution TS1) is like MR, but includes the equatorial damper $\delta$. The difference, MR - TS1 (Solution EQ), then illustrates the effects of remote forcing only by the reflection of equatorial Kelvin waves off Sumatra (process 3). It also includes the effect of direct wind forcing within the 
region covered by $\delta$, but this effect is not large because interannual wind forcing is weak there (Figure 6).

The second solution (Solution TS2) is like MR, except that boundary conditions (4) are replaced by

$$
\begin{gathered}
\tilde{u}_{n}=\boldsymbol{n} \cdot \boldsymbol{v}_{n}=-\boldsymbol{n} \cdot \boldsymbol{k} \times \frac{\mathbf{F}_{n}}{f}, \\
\tilde{v}_{n}=\boldsymbol{k} \times \boldsymbol{n} \cdot \boldsymbol{v}_{n}=0,
\end{gathered}
$$

where $\boldsymbol{n}$ is a unit vector normal to the boundary, $\boldsymbol{k}$ is a unit vector directed upward, $\boldsymbol{v}_{n}=\left(u_{n}, v_{n}\right), \tilde{u}_{n}$ and $\tilde{v}_{n}$ are velocity components perpendicular and parallel to the boundary, and $\boldsymbol{F}_{n}=\left(F_{n}, G_{n}\right)$. The unit vector $\boldsymbol{n}$ points out of the Bay of Bengal (inshore) along its eastern and northeastern margins, into the bay (offshore) along its northern and western margins, out of the sea (inshore) along the southern boundaries of India and Sri Lanka and along their west coast (eastern Arabian Sea), and into the sea (offshore) along the northern and western boundaries of the Arabian Sea (Shankar et al., 2002). According to (5), Ekman drift is allowed to pass through continental boundaries north of $3.5^{\circ} \mathrm{N}$. The difference, MR $-\mathrm{TS} 2$ (Solution CST), then illustrates only the effects of forcing by coastal alongshore winds in the northern Indian Ocean (process 2). (Solution CST is equivalent to Process AW of Shankar et al. (2002).)

The third process solution (Solution INT) includes both $\delta$ and boundary conditions (5), eliminating effects of both reflection off Sumatra and of alongshore winds in the north Indian Ocean. This solution (process 1) therefore shows the effects of direct forcing by winds in the interior ocean, including the generation of Kelvin waves in the equatorial ocean and of Rossby waves. It also includes the equatorial Kelvin wave generated by the reflection of the Rossby wave at the 
western boundary of the basin. Though this reflection is not part of the directly forced response, we often use the term "directly forced" to refer to this process solution (INT). Note that INT $=$ MR - EQ - CST, a statement that MR is in fact equal to the sum of the three process solutions.

\subsubsection{Results}

Figure 5 plots wavelet power from Solutions EQ (top right panel), CST (middle left panel), and INT (middle right panel). Since the alongshore winds are weak at a period of 3 years (Figure 6), the response to these winds (Solution CST) is negligible in comparison to the impact of the other two processes. Solution EQ is essentially driven by the sea-level signal at the eastern equatorial boundary. Coastal Kelvin waves spread the equatorial response poleward along the eastern boundary, so that sea level is essentially constant along it. Since there is no forcing for Solution EQ in the interior ocean, the eastern-coastal response then extends into the interior ocean via Rossby-wave propagation, weakening away from the EEIO owing to the equatorial damper $\delta$ and vertical mixing (the terms proportional to $A / c_{n}^{2}$ in (3)). In contrast, Solution INT is forced throughout the interior ocean by Ekman pumping and has little or no response along the eastern boundary, since almost all of that response is being absorbed into EQ. It has a more complex structure than does Solution EQ, which is determined by the eastern-boundary sea level.

Figure 3 also plots low-pass-filtered time series for Solutions EQ and INT. It is evident that minima (maxima) occur at locations where the two solutions interfere destructively (constructively), tending to cancel (enhance) each other. Cancellation of EQ and INT occurs, for example, in the CEIO. Since the spatial variation of EQ is small (Figure 5), it is essentially the spatial variation of INT 
that determines the location of the minima. In the EEIO, the interannual wind forcing is weak, leading to a dominance of EQ over INT and a strong sea-level response there. In the WEIO, although EQ and INT tend to counterbalance each other, the EQ response is slightly weaker than in the EEIO owing to damping, and the local wind forcing is just a little stronger, producing a stronger net sea-level response (and stronger variability) in the WEIO in comparison to CEIO. A similar cancellation of EQ and INT holds for all the minima (Figure 3).

\subsection{Longer periods}

The discussion so far has been restricted to a period of 3 years or less because the short altimeter record precludes an analysis of higher periodicities; periods greater than 3 years fall outside the cone of influence of the wavelet power spectrum (Figure 4).

Our simulations, however, extend from 1948-2004 and can resolve periods up to 10 years. These simulations show that the model response is practically the same over the period range from 17-20 months to about 6 years (Figure 8; figure not shown for 6 years). The similarities are striking, but there are subtle differences with period, the differences being most notable in the southwestern Bay of Bengal, in the regime of the thermal domes (Vinayachandran and Yamagata, 1998). An examination of the process solutions (not shown) shows that these differences arise as a consequence of differences in Solution INT, the EQ response changing much less with period.

At a period of 10 years, however, the minimum in the central Indian Ocean shifts southwestward and is centered at $5^{\circ} \mathrm{S}$ (Figure 8). There is still a minimum in the CEIO relative to the maximum in the EEIO (compare the two bottom panels in Figure 9), but the variability in the vicinity of the equator is greater than that 
to the southwest. The minima along the eastern and northern boundaries of the Arabian Sea still exist, as do the minima along the coast of Oman and the Gulf of Aden, along the southwestern boundary of the Bay of Bengal, and to the east of the thermal dome (Figure 8).

Thus, the explanation for the existence of the minima holds at higher periods too: it is the cancellation of Solutions INT and EQ that causes the minima (bottom panels of Figure 8). At the 10-year period, however, there are some differences to be noted. First, the structure of the wind forcing is different. The zonal wind at the equator is no longer confined to the CEIO and the alongshore winds are not negligible, unlike for the period range 17 months to 6 years (Figure 6). Hence, the destructive interference is a 3-way cancellation in regions affected by Solution CST. Second, as a consequence of the alongshore winds being stronger, the zonal variation of Ekman pumping at this period, though still much weaker than at the annual period, is much greater than at any other interannual period (Figure 7). This zonal variation of the INT forcing leads to changes in the spatial structure of the interannual-variability maxima and minima in comparison to the interannual period band from 17-20 months to 6 years.

We do not, however, have basin-wide sea-level data to decide if these features are realistic. At the 10-year period, the model minimum at $5^{\circ} \mathrm{S}$ also contains an uncertainty arising from the closed boundary in the east, this closed boundary precluding exchange of mass between the Indian and Pacific Oceans via the Indonesian Throughflow, and therefore also precluding the impact of the interannual variability associated with it on the interannual variability of sea level in the south Indian Ocean. 


\section{Basic dynamics}

In Section 3, we have shown that minima at a broad range of interannual time scales result from destructive interference between the directly forced (INT) and reflected-Rossby-wave (EQ) responses. Here, we use an idealized version of the numerical model to demonstrate that they are an aspect of the quasi-steady (nearequilibrium) response of the ocean, which is approximately valid in the tropics at interannual time scales.

We begin with a general discussion of quasi-stationarity (Section 4.1), then report an analytic solution for a quasi-steady approximation to the LCS model (Section 4.2), and then present idealized numerical solutions (Section 4.3) that bridge the gap between the analytic solution and the realistic numerical solutions presented in Section 3. The section concludes with a discussion of the easternboundary pressure field (Section 4.4).

\subsection{Quasi-steady response}

\subsubsection{Period independence}

The minima occur at all time scales greater than about 17 months and at all these interannual periods, the mechanism is the same: there is destructive interference between the directly-forced and reflected-wave responses. Furthermore, as long as the wind forcing patterns are similar for different interannual periods (Section 3.5), the patterns of the response are also similar. Thus, the mechanism is independent of period as long as it is greater than the annual, suggesting a quasisteady balance at interannual periods.

\subsubsection{Contributions from individual modes}

Minima are present in the CEIO for both the first-mode and second-mode responses, but the second-mode minimum is a little stronger (weaker variability) 
(bottom panels of Figure 5). This lack of sensitivity to the vertical modenumber distinguishes the model response at interannual periods from that at the annual or semiannual periods, for which the first- and second-mode responses are very different, there being a resonant response of the equatorial Indian Ocean for the second mode (Jensen, 1993; Clarke and Liu, 1993; Han et al., 1999; Blanc and Boulanger, 2001). As modenumber increases, however, the damping term $A / c_{n}^{2}$ becomes important and the interannual response is no longer independent of modenumber; at these higher modes, however, the ocean couples much more weakly to the wind than do the first two modes, and therefore it is primarily the first two modes that determine the overall model response, as in McCreary et al. (1996). That the response is independent of modenumber also suggests a quasi-steady balance.

\subsubsection{Basin adjustment time scale}

In the LCS model, baroclinic waves for the first and second modes take just a few months to cross the basin. For the first mode, the equatorial Kelvin wave takes just one month to cross and the lowest-meridional-mode Rossby wave takes 3 months (Blanc and Boulanger, 2001); for the second mode, the waves take about twice as long (Shankar et al., 1996), implying an equatorial adjustment time scale of about 8 months. Rossby-wave speeds slow appreciably with latitude $\left(\sim y^{-2}\right)$, and at, say, $20^{\circ} \mathrm{N}$, they take 15 and 38 months to cross the basin for the first and second modes. At interannual periods and within the tropics, then, the forcing time scale is longer than the adjustment time scale of the system. Therefore, circulations in the tropical ocean can be assumed to respond in a quasi-steady fashion to the slowly varying (interannual) forcing. (See Section 4.4 for a more detailed discussion of this quasi-steady assumption.) 


\subsection{Analytic solution}

\subsubsection{The analytic model}

The equations of motion of our idealized model are a simplified form of (3) without time derivatives and most mixing terms, the former restriction being the "quasi-steady" assumption. The equations are

$$
\begin{gathered}
-f v+p_{x}=F+v_{2} u_{y y}, \\
f u+p_{y}=v_{2} v_{x x}, \\
u_{x}+v_{y}=0
\end{gathered}
$$

where, for convenience, subscripts $n$ are dropped and the factor of $\bar{\rho}$ is absorbed into the pressure. We formally retain the terms $v_{2} v_{x x}$ and $v_{2} u_{y y}$, allowing for the existence of frictional western, northern, and southern boundary currents; however, we assume that $v_{2}$ is very small (tends to zero) so that the widths of the boundary currents are negligible and the interior ocean adjusts to the inviscid, Sverdrup balance.

The ocean basin is a rectangular domain extending latitudinally from $y_{s}=$ $20^{\circ} \mathrm{S}$ to $y_{n}=20^{\circ} \mathrm{N}$ and longitudinally from $x_{w}=50^{\circ} \mathrm{E}$ to $x_{e}=100^{\circ} \mathrm{E}$, and India is represented by a line segment along $x=x_{1}=75^{\circ} \mathrm{E}$ from $y_{1}=6^{\circ} \mathrm{N}$ to $20^{\circ} \mathrm{N}$. (The northern boundary of this domain is chosen to coincide with that of the Bay of Bengal in the numerical model.) With India thus represented, the basin is divided into three regions: the "interior Indian Ocean" $\left(y<6^{\circ} \mathrm{N}\right)$, the Bay of Bengal $(x>$ $\left.x_{1}, y \geq 6^{\circ} \mathrm{N}\right)$, and the Arabian Sea $\left(x<x_{1}, y \geq 6^{\circ} \mathrm{N}\right)$.

For simplicity, we assume that $\tau^{x}=\tau_{o} Y(y)$, so that the wind is $x$-independent. Such a form for the wind forcing is suggested by the interannual wind field (Figure 6). The forcing for the model is then $F=\tau_{o}\left(Z_{n} / \mathcal{H}_{n}\right) Y(y) \equiv F_{o} Y(y)$. 


\subsubsection{Solution}

The flow field is most easily obtained in terms of the streamfunction $\psi$ defined by

$$
v=\psi_{x}, \quad u=-\psi_{y} .
$$

It follows from (6) that $\psi_{x}=-F_{y} / \beta$, yielding

$$
\psi=-\frac{F_{o}}{\beta}\left(x-x_{e}\right) Y_{y}
$$

for the interior Indian Ocean and Bay of Bengal, and

$$
\psi_{A S}=-\frac{F_{o}}{\beta}\left(x-x_{1}\right) Y_{y}
$$

for the Arabian Sea, both integrations subject to the boundary condition that $\psi=0$ along the eastern boundary of their specific region. Note that there is a jump in $\psi$ along the southern boundary of the Arabian Sea $\left(y=6^{\circ} \mathrm{N}\right)$; thus, at $y=6^{\circ} \mathrm{N}$, there is a $\delta$-function zonal jet, which would be broadened in a model with interior mixing. In addition, values of $\psi$ and $\psi_{A S}$ just offshore from the western, northern, and southern boundaries (i. e., along $x=x_{w}^{+}, x=x_{1}^{+}, y=y_{n}^{-}$, and $y=y_{s}^{+}$) are generally not zero, so that $\delta$-function boundary currents are present there as well.

The pressure fields in the interior Indian Ocean and Bay of Bengal are found by integrating the first of equations (6) from $x_{e}$ and using (8a), yielding

$$
p=p_{e}-F_{o}\left(x_{e}-x\right)\left(Y-y Y_{y}\right)
$$

where $p_{e}$ is an as yet unspecified pressure along the eastern boundary. Note that, because the mixing term $v_{2} v_{x x}$ is assumed negligible, the second of equations (6) requires that $p_{e}$ is constant everywhere along the boundary. Similarly, the pressure in the Arabian Sea is

$$
p_{A S}=p_{11}-F_{o}\left(x_{1}-x\right)\left(Y-y Y_{y}\right)
$$


where $p_{11}=p_{1}\left(y_{1}\right)$, defined next in (10), is the pressure at the tip of India ( $x=x_{1}$, $y=y_{1}$ ) and, by the second of equations (6), all along its west coast.

The pressures along the western boundaries can be obtained without actually solving for the boundary-current structures (meridional and zonal Munk layers), by integrating the first of equations (6) across their respective regions so that the zonal integral of $\psi_{x}$ vanishes (since $\psi=0$ along all boundaries). The pressure along the east coast of India $\left(p_{1}\right)$ is then

$$
p_{1}(y)=p_{e}-F_{o}\left(x_{e}-x_{1}\right) Y(y),
$$

and that along the western boundary of the basin $\left(p_{w}\right)$ is

$$
p_{w}(y)=\left\{\begin{array}{cc}
p_{11}-F_{o}\left(x_{1}-x_{w}\right) Y(y), & y \geq 6^{\circ} \mathrm{N}, \\
p_{e}-F_{o}\left(x_{e}-x_{w}\right) Y(y), & y<6^{\circ} \mathrm{N} .
\end{array}\right.
$$

Note that $p_{w}$ is continuous at $y_{1}=6^{\circ} \mathrm{N}$, since $p_{11}=p_{1}\left(y_{1}\right)$. Similarly, the pressures along the northern $\left(p_{n}\right)$ and southern $\left(p_{s}\right)$ boundaries, obtained by integrating the first of equations (6) with $v=0$ across their respective basins, are

$$
p_{n}(x)=\left\{\begin{array}{lc}
p_{e}-\left(x_{e}-x\right) F_{o} Y\left(y_{n}\right), & x>x_{1}, \\
p_{11}-\left(x_{1}-x\right) F_{o} Y\left(y_{n}\right), & x<x_{1},
\end{array}\right.
$$

and

$$
p_{s}(x)=p_{e}-\left(x_{e}-x\right) F_{o} Y\left(y_{s}\right) .
$$

As for the streamfunction field, there are generally pressure jumps offshore from the western, northern, and southern boundaries, indicative of boundary currents.

It remains to specify $p_{e}$. Suppose the wind is switched on and that initially pressure is zero everywhere. Since the basin is closed and western boundary regions are negligibly narrow, it follows from (6) that interior pressure is conserved 
in the domain at all times. In equilibrium, then,

$$
\iint_{\mathcal{A}} p d x d y+\iint_{\mathcal{A}^{\prime}}\left(p_{A S}-p\right) d x d y=0
$$

where $\mathcal{A}$ is the area of the entire basin and $\mathcal{A}^{\prime}$ is the area of the Arabian Sea. Constraint (14) provides the additional condition necessary to determine $p_{e}$. With the aid of (9), (14) gives

$$
\frac{\mathcal{A}}{F_{o}} p_{e}=\left(x_{e}-x_{w}\right)^{2} \int_{y_{s}}^{y_{n}} Y d y+\left(x_{e}-x_{1}\right)\left(x_{1}-x_{w}\right)\left[\left(y_{n}-2 y_{1}\right) Y\left(y_{1}\right)-2 \int_{y_{1}}^{y_{n}} Y d y\right] \text {, }
$$

where we use the identity that $Y-y Y_{y}=2 Y-(y Y)_{y}$.

\subsubsection{Example}

To illustrate the solution, we assume that

$$
Y(y)=\frac{1}{2}\left(1+\cos \frac{\pi y}{L}\right) \theta(L-|y|),
$$

where $\theta$ is a step function and $L=20^{\circ}$, implying a zonally invariant Ekman pumping field in the interior ocean. A comparison with the wind forcing along the equator and the Ekman pumping field at the 3-year period (Figure 6) suggests that this approximation is a reasonable representation of the structure of the observed interannual wind field. With this choice for $Y$,

$$
p_{e}=\Delta x \frac{L}{\Delta y}\left\{1+\frac{1}{4}\left[\left(\frac{y_{n}}{L}-\frac{2 y_{1}}{L}\right) Y\left(y_{1}\right)-\frac{2}{L} \int_{y_{1}}^{L} Y d y\right]\right\}=0.96 \Delta x F_{o},
$$

where $\Delta x=x_{e}-x_{1}=x_{1}-x_{w}$ and $\Delta y=\left(y_{n}-y_{s}\right) / 2$.

Figure 10 plots the resulting interior $\psi$, sea-level $d=p / g$, and $|d|$ fields for a single mode $n$ with $Z_{n}=1, \mathcal{H}_{n}=H$, and $\tau_{o}=0.22 \mathrm{dyn} \mathrm{cm}^{-2}$. The value used for $\tau_{o}$ is the maximum (over the 57-year period 1948-2004) amplitude of the lowpass-filtered wind at equator in the region $75-90^{\circ} \mathrm{E}$,). In order that the analytic 
solution compares better with the numerical solutions found in Section 4.3, we decrease the eastern-boundary pressure to $p_{e}=0.5 \Delta x F_{o}$. (A discussion on this choice of $p_{e}$ follows in Section 4.4.) South of the equator, the circulation consists of a large gyre that extends across the basin, with eastward flow near the equator and westward flow farther to the south (top-left panel of Figure 10), the two branches closed by a northward western boundary current along $x_{w}$. Analogous gyres, but rotating opposite to the south-Indian-Ocean gyre, exist in the Bay of Bengal and Arabian Sea; both gyres are closed by southward western boundary currents. There is a discontinuity in $\psi$ and in $p$ west of India along $6^{\circ} \mathrm{N}$, corresponding to a westward current from the bay that crosses the Arabian Sea; at the western boundary, it bends southward and then eastward just north of the equator to return to the bay.

Because $\tau_{o}>0, d$ slopes down everywhere from east to west in the latitude band of the wind, which covers the entire domain $\left(|y| \leq 20^{\circ}\right.$; top-right panel of Figure 10). Sea level is zero along the black curve, and the $|d|$ map illustrates the regions of minimum $d$ centered about the line. Similar to the variability maps for the numerical solution and altimeter data, minima stand out in the southwest Bay of Bengal, in the CEIO, and near the eastern and northern coasts of the Arabian Sea. The latter features are a direct consequence of the presence of India, since without India the solution in the Arabian Sea is a mirror image of that in the southern hemisphere (bottom-right panel of Figure 10). Note that the $\psi$ and $d$ fields would reverse for $\tau_{o}<0$, but the minima, as represented by $|d|$, would remain. 


\subsection{Numerical analogs}

To bridge the gap between the analytic solution and the numerical solutions forced by realistic winds, we obtained four solutions to the numerical model of Section 3. Each is forced by an idealized wind field with the meridional structure (16) that varies sinusoidally in time with a 3-year period. The four solutions differ in the basin geometry and in the zonal structure of the wind (Solution 4).

\subsubsection{Rectangular basin}

Solution 1 uses the same rectangular domain as for the analytic model with India represented by a strip (top-left panel of Figure 11) and $x$-independent forcing. Wavelet power for the numerical solution is similar to that for sea level in the analytic solution, there being a minimum in the CEIO and the southwestern bay. The structure of the CEIO minimum, with its two lobes, is that of an equatorial Rossby wave. A steady-state forcing in this numerical model produces a response (not shown) similar to the analytic solution, but the former is smoother owing to the presence of lateral mixing.

Solution 2 is like Solution 1, but without the strip representing India (top-right panel of Figure 11). As expected, there is now a maximum in the eastern Arabian Sea to the north of the CEIO minimum, just as in the southern hemisphere. Most striking is the impact of India on the interannual variability in the Arabian Sea north of $6^{\circ} \mathrm{N}$, the latitude of the southern tip of India. In the absence of India, the maximum in the northern bay extends across the basin to the west.

Hence, the minima in the northern and northwestern Arabian Sea are due to the presence of India, which permits communication via coastal Kelvin waves between the western boundary of the Bay of Bengal and the eastern boundary of the Arabian Sea. The sea-level response at the southern tip of the Indian sub- 
continent spreads essentially instantaneously (in comparison to interannual time scales) along the west coast of India. This adjustment is implicit in equations (9b) and (10) in the analytic model and in the model of Clarke and Liu (1994), who used tide-gauge data to study interannual, wind-forced sea-level variability along the Indian coast. The resulting minimum at the northeastern corner of the Arabian Sea leads to a minimum along the northern boundary of the Arabian Sea. This minimum provides a sharp contrast to the northern Bay of Bengal, which shows a maximum because it is similarly connected via Kelvin waves (Potemra et al., 1991; Yu et al., 1991; McCreary et al., 1993, 1996) to the maximum in the eastern Bay of Bengal and EEIO.

\subsubsection{Realistic basin geometry}

Solution 3 uses the same basin geometry as in Section 3, but has the same idealised forcing as for Solutions 1 and 2. The resulting wavelet power is shown in the bottom-left panel of Figure 11. As for Solution 1, the minimum off the Indian west coast spreads along the northern boundary of the Arabian Sea, and as for the numerical simulations forced by realistic winds (Figure 5), this minimum extends counterclockwise along the coast of Oman and into the Gulf of Aden. The southern limit of this minimum is marked by the maximum off Somalia. Hence, the minimum in the Gulf of Aden also owes its existence to the presence of India.

In the southern Bay of Bengal, the analytic solution (Figure 10) and the numerical simulation with idealized winds (Figure 11) differ from the numerical

simulation with realistic winds (Figure 5). The simpler solutions produce a minimum in the regime of the Sri Lanka dome and a relative maximum near the southwestern boundary and to the east of the dome, which is opposite to the variability seen in the observations (Figure 1) and numerical simulations with realistic winds 
(Figure 5). The cause of this difference lies in the wind forcing: the wind field in this region is more complex than the idealized, zonally invariant wind field, there being a zonal variation in Ekman pumping across the southern Bay of Bengal (Figure 7).

Apart from this difference in the southern bay, Solution 3 differs in two key respects from the solution forced by the NCEP winds (Figure 5). First, the minimum in the CEIO appears as two distinct lobes on either side of the equator instead of a single, big patch centered on the equator. Second, the minimum off the Indian west coast is separated from the coast by a relative maximum. To determine the impact of the zonal structure of $\tau_{o}$ on the structure of the response, we restricted the wind forcing to the longitude band in which the observed the observed, 3-yearperiod, zonal wind is strong. Hence, Solution 4 is similar to Solution 3, except that the zonal extent of the idealized wind was restricted to $75-90^{\circ} \mathrm{E}$ and tapered nonlinearly to zero at $40^{\circ} \mathrm{E}$ and $100^{\circ} \mathrm{E}$. This change in forcing decreases the separation between the two lobes of the CEIO minimum and tends to eliminate the separation of the west-coast minimum from the coast (bottom-left panel of Figure 11), demonstrating that the zonal structure of the zonal wind has a significant impact on the oceanic response at interannual periods, as had been noted earlier (Han et al., 1999) for the annual and semiannual periods.

\subsection{Eastern-boundary pressure $p_{e}$}

A key variable in the analytic model is the eastern-boundary pressure, $p_{e}$, which represents the reflected Rossby wave of the numerical analog. As noted in Section 4.2, the analytic solution that compares best with its numerical analogs requires a lower value of $p_{e}$ than predicted by (17). Several factors contribute to this difference. 


\subsubsection{Lack of quasi-stationarity}

The most important factor is that, even at interannual time scales, the response is still not in a quasi-steady state. As discussed in Section 4.1, a measure of the adjustment time for the tropical circulation is the time taken for Rossby waves to travel across the basin. Outside the tropics, however, it takes first- and secondmode Rossby waves much longer to cross the basin. Near the southern boundary of the basin $\left(29^{\circ} \mathrm{S}\right)$, for example, it takes them 9 and 23 years respectively to cross the basin, and the quasi-steady-state approximation no longer holds at periods of 3-6 years. Furthermore, the above times represent only the minimum adjustment times, as the approach to a final steady state requires multiple reflections of Rossby waves and equatorially trapped Kelvin waves. Thus, although the structure of the tropical currents is quasi-steady, the value $p_{e}$ is not because it requires basin-wide adjustments of the mass field.

\subsubsection{Damping}

The numerical model also includes damping $\left(A / c_{n}^{2}\right)$, implying that mass (or pressure) is not strictly conserved in spite of the basin being closed. It is the loworder modes, however, that dominate the surface pressure field in our solutions, and damping for them is weak. Hence, although damping will impact $p_{e}$ to some degree, its effects are weak.

\subsubsection{Slanted eastern boundary}

Another complication occurs in the numerical solutions forced by idealized (zonally invariant) winds and found in realistic basins. In that case, the zonal winds have an alongshore component along the eastern boundary, and so $p_{e}$ varies with latitude, thereby influencing the basin-wide mass balance. 


\subsubsection{Southern-boundary condition}

Finally, we note that the southern boundary is open in the real Indian Ocean, and hence the area integral of pressure (mass) is not conserved. In this case, the value of pressure at the southwest corner of the basin (tip of Africa) is determined externally, which we can, without loss of generality, assume is zero. In steady state, there can be no net mass flow into or out of the basin. Since there is no Ekman flow across the southern boundary because $Y(y)=0$ at $y_{s}$, there can be no net geostrophic flow there either, and it follows that $p_{e}=0$. It follows that the only way that $p_{e} \neq 0$ is in a transient situation, that is, $p_{e}$ is not quasi-steady.

\section{Discussion}

We have shown that a simple explanation ties together the several minima in interannual sea-level variability seen in the equatorial and north Indian Ocean: the minima are a result of the quasi-steady balance that prevails when the wind varies sufficiently slowly. Specifically at interannual periods and in the tropics, the adjustment time scale of the basin is sufficiently smaller than the forcing period for the quasi-steady approximation to become viable. In support of this idea, the horizontal structures of our interannual (periods from 17-20 months to $\sim 6$ years) solutions are nearly independent of period and, for the low-order vertical modes, for which mixing is weak, also of vertical modenumber, (Section 4.1). Minima exist wherever the quasi-steady, Sverdrup-balanced circulation (Solution INT) cancels the response to the reflection of equatorial Kelvin waves from the eastern boundary (Solution EQ). Furthermore, a key element of the interannual variability in the Arabian Sea is the existence of India, which has a major impact on the response in most of the basin; in particular, it accounts for the minimum that 
extends around the perimeter of the Arabian Sea from the west coast of India to Oman.

It is noteworthy that the spatial structures of the wind forcing at interannual periods are also similar (Figure 6). Hence, even though it is possible to separate the 18-20-month and 3-year bands in a spectrum (Sakova et al., 2006), they appear to be part of the same, broad-band, interannual-period variability of the sea-level field. At its high-period limit, the band merges into the periodicities associated with ENSO and IODZM. At its low-period limit ( 17-20 months), the band already shows a striking difference in both forcing (Figure 6) and sealevel response from the annual period (compare top right and bottom left panels of Figure 1). Sakova et al. (2006) note that their spectral analysis did not show a quasi-biennial periodicity, but it is likely that the period range from 17 months to about 3 years is part of this phenomenon.

It has been almost four decades since the coarsely-sampled, bimonthly, hydrographic data from the International Indian Ocean Expedition (Wyrtki, 1971) conducted during the 1960s and the seminal work of Lighthill (1969) stamped time-dependence as a basic characteristic of the north Indian Ocean. That was also the beginning of the satellite era. It is ironic that it has taken the high-resolution temporal and spatial sampling of the altimeter to enable a viable quasi-steady theory that yields insights into the low-frequency variability of the Indian Ocean. The dynamics invoked here is simple, but should be extendable to other basins for which the interannual wind field can be approximated by a similar function. We are currently looking at the Pacific Ocean: a similar minimum exists in the central equatorial Pacific.

Given the strong correlation between sea level and thermocline depth (or depth 
of a given, say $25^{\circ} \mathrm{C}$, isotherm), it follows that low variability of sea level corresponds to a low variability of the thermocline. Regions of high thermocline variability, like the EEIO (IODZM) or the "thermocline ridge" (Annamalai et al., 2005 ) in the southwest Indian Ocean around $10^{\circ} \mathrm{S}$, have been shown to play a role in the climate of the region. In both these regions, the altimeter data and model showed maxima of interannual sea-level variability (Figure 5). The variability of the thermocline is also important for biogeochemistry. What, then, is the implication, if any, of these minima, where interannual sea-level variability is low at all times? Are these minima only a beautiful dynamical curiosity, or do they have a larger impact?

\section{Acknowledgments}

D. Shankar, M. Aparna, I. Suresh, S. Neetu, and S. S. C. Shenoi acknowledge support from the Council of Scientific and Industrial Research (CSIR) under the Supra-Institutional Project and from the Ministry of Earth Sciences (New Delhi, India). J. P. McCreary acknowledges support from NIO under the Adjunct Scientist Scheme of CSIR during 2007-2009, and also acknowledges support from the Japan Agency for Ocean and Earth Science and Technology (JAMSTEC), the Na-

tional Aeronautics and Space administration (NASA), and the National Oceanic and Atmospheric Administration (NOAA) through their sponsorship of the IPRC. M. A. Al Saafani acknowledges support from the Government of Yemen and the facilities provided by the National Institute of Oceanography, Goa. F. Durand acknowledges support from IRD/LEGOS, France. Weiqing Han provided the results of her simulations from the work of Han and Webster (2002). The wavelet software was downloaded from http://paos.colorado.edu. Ferret was used for analysis 
and graphics. All computations were done on the SGI cluster in NIO. This is NIO contribution xxxx, SOEST contribution yyyy, and IPRC contribution 636.

\section{References}

AlSaafani, M. A., Shenoi, S. S. C., Shankar, D., Aparna, M., Kurian, J., Durand, F., Vinayachandran, P. N., 2007. Westward movement of eddies into the Gulf of Aden from the Arabian Sea. Journal of Geophysical Research 112, 3141-3155.

Annamalai, H., Murtugudde, R., 2004. Role of Indian Ocean in regional climate variability. Geophysical monograph 147, 213-246.

Annamalai, H., Xie, S. P., McCreary, J. P., Murtugudde, R., 2005. Impact of Indian Ocean sea surface temperature on developing El Niño. Journal of Climate 18, $302-319$.

Ashok, K., Guan, Z., Saji, N. H., Yamagata, T., 2004. Individual and combined influences of ENSO and the Indian Ocean Dipole on the Indian Summer Monsoon. Journal of Climate 17, 3141-3155.

AVISO, 1996. AVISO User Handbook: Merged TOPEX/Poseidon Products. Toulouse, France.

Blanc, J. L. L., Boulanger, J. P., 2001. Propagation and reflection of long equatorial waves in the Indian Ocean from TOPEX/Poseidon data during 1993-1998. Climate Dynamics 17, 547-557.

Böhm, E., Morrison, J. M., Manghnani, V., Kim, H., Flagg, C., 1999. Remotely sensed and acoustic doppler current profiler observations of the Ras al Hadd Jet. Deep-Sea Research II 46, 1531-1549. 
Brandt, P., Stramma, L., Schott, F., Fischer, J., M.Dengler, Quadfasel, D., 2002. Annual Rossby waves in the Arabian Sea from TOPEX/Poseidon altimeter and in situ data. Deep-Sea Research II 49, 1197-1210.

Chang, P., Yamagata, T., Schopf, P., Behera, S. K., Carton, J., Kessler, W. S., Meyers, G., Qu, T., Schott, F., Shetye, S. R., Xie, S. P., 2006. Climate fluctuations of tropical coupled systems — the role of ocean dynamics. Journal of Climate $19,5122-5174$.

Clarke, A. J., Liu, X., 1993. Observations and dynamics of semiannual and annual sea levels. Journal of Physical Oceanography 23, 386-399.

Clarke, A. J., Liu, X., 1994. Interannual sea level in the northern and eastern Indian Ocean. Journal of Physical Oceanography 24, 1224-1235.

DeMoortel, I., Munday, S. A., Hood, A. W., 2004. Wavelet analysis: The effect of varying basic wavelet parameters. Solar Physics 222, 203-228.

Ducet, N., Traon, P. Y. L., Reverdin, G., 2000. Global high-resolution mapping of ocean circulation from the combination of T/P and ERS-1/2. Journal of Geophysical Research 105, 19477-19498.

Durand, F., Shankar, D., Birol, F., Shenoi, S. S. C., 2008. Estimating boundary currents from satellite altimetry: A case study for the east coast of India. Journal of Oceanography $64,831-845$.

Durand, F., Shankar, D., Birol, F., Shenoi, S. S. C., 2009. Spatio-temporal structure of the east india coastal current from satellite altimetry. Journal of Geophysical Research, in Press. 
Durand, F., Shankar, D., Montegu, C. D., Shenoi, S. S. C., Blanke, B., Madec, G., 2007. Modeling the barrier-layer formation in the southeastern Arabian Sea. Journal of Climate 20, 2109-2120.

Findlater, J., 1969. A major low-level air current near the Indian Ocean during the northern summer. Quarterly Journal of the Royal Meteorological Society 95, $362-380$.

Fu, L. L., Smith, R. D., 1996. Global ocean circulation from satellite altimetry and high-resolution computer simulation. Bulletin of the American Meteorological Society 77, 2625-2636.

Han, W., McCreary, J. P., Anderson, D. L. T., Mariano, A. J., 1999. On the dynamics of the eastward surface jets in the equatorial Indian Ocean. Journal of Physical Oceanography 29, 2191-2209.

Han, W., McCreary, J. P., Kohler, K. E., 2001. Influence of precipitation minus evaporation and Bay of Bengal rivers on dynamics, thermodynamics, and mixed layer physics in the upper Indian Ocean. Journal of Geophysical Research 106, 6895-6916.

Han, W., Webster, P. J., 2002. Forcing mechanisms of sea-level interannual variability in the Bay of Bengal. Journal of Physical Oceanography 23, 216-239.

Hankin, S., Callahan, J., Manke, A., O’Brien, K., Li, J., 2006. Ferret User Guide. PMEL, NOAA, U.S.A.

Jensen, T. G., 1993. Equatorial variability and resonance in a wind-driven Indian Ocean model. Journal of Geophysical Research 98, 22533-22552. 
Jensen, T. G., 2003. Cross-equatorial pathways of salt and tracers from the northern Indian Ocean: Modelling results. Deep-Sea Research II 50, 2111-2127.

Kalnay, E., Kanamitsu, M., Kistler, R., Collins, W., Deaven, D., Gandin, L., Iredell, M., Saha, S., White, G., Woollen, J., Zhu, Y., Chelliah, M., Ebisuzaki, W., Higgins, W., Janowiak, J., Mo, K. C., Ropelewski, C., Wang, J., Leetmaa, A., Reynolds, R., Jenne, R., Joseph, D., 1996. The NCEP/NCAR 40-year reanalysis project. Bulltien of American Meterological Society 77, 437-471.

Knox, R. A., 1976. On a long series of the Indian Ocean equatorial currents near Addu Atoll. Deep-Sea Research 23, 211-221.

Kurian, J., Vinayachandran, P. N., 2007. Mechanisms of formation of Arabian Sea mini warm pool in a high-resolution OGCM. Journal of Geophysical Research 112.

Levitus, S., 1982. Climatological atlas of the world ocean. NOAA Professional Paper 13, 173 pp., U.S. Government Printing Office, Washington D.C.

Lighthill, M. J., 1969. Dynamic response of the Indian Ocean to onset of the southwest monsoon. Philosophical Transactions of the Royal Society of London 265, $45-92$.

Luyten, J. R., Roemmich, D. H., 1982. Equatorial currents at semiannual period in the Indian Ocean. Journal of Physical Oceanograhy 12, 406-413.

Masumoto, Y., Meyers, G., 1998. Forced Rossby waves in the southern tropical Indian Ocean. Journal of Geophysical Research 103, 27589-27602. 
McCreary, J. P., 1980. Modelling wind-driven ocean circulation. Technical Report, Univ of Hawaii 80, 64pp.

McCreary, J. P., 1981. A linear stratified ocean model of the Equatorial Undercurrent. Philosophical Transactions of the Royal Society of London 298, 603-635.

McCreary, J. P., Han, W., Shankar, D., Shetye, S. R., 1996. Dynamics of the East India Coastal Current, 2. Numerical solutions. Journal of Geophysical Research 101, 13993-14010.

McCreary, J. P., Kundu, P. K., Molinary, R. L., 1993. A numerical investigation of the dynamics, thermodynamics and mixed layer processes in the Indian Ocean. Progress in Oceanography 31, 181-224.

McCreary, J. P., Miyama, T., Furue, R., Jensen, T., Kang, H. W., Bang, B., Qu, T., 2007. Interactions between the Indonesian Throughflow and circulations in the Indian and Pacific Oceans. Progress in Oceanography 75, 70-114.

McCreary, J. P., Shetye, S. R., Kundu, P. K., 1986. Thermohaline forcing of eastern boundary currents: with application to the circulation off the west coast of Australia. Journal of Marine Research 44, 71-92.

Moore, D. W., McCreary, J. P., 1990. Excitation of intermediate-frequency equatorial waves at a western boundary: with application to observations from the western Indian Ocean. Journal of Geophysical Research 96, 2515-2534.

Murtugudde, R., Busalacchi, A., 1999. Interannual variability of the dynamics and thermodynamics of the tropical Indian Ocean. Journal of Climate 12, 23002326. 
Murtugudde, R., Busalacchi, J., Beauchamp, J., 1998. Seasonal to interannual effects of the Indonesian Throughflow on the tropical Indo-Pacific basin. Journal of Geophysical Research 103, 21425-21441.

Murtugudde, R., McCreary, J. P., Busalacchi, J., 2000. Oceanic processes associated with anomalous events in the Indian Ocean with relevance to 1997-1998. Journal of Geophysical Research 105, 3295-3306.

Nethery, D., Shankar, D., 2007. Vertical propagation of baroclinic Kelvin waves along the west coast of India. Journal of Earth System Science 116, 331-339.

Patullo, J., Munk, W., Revelle, R., Strong, E., 1955. The seasonal oscillation in sea level. Journal of Marine Research 14, 88-156.

Perigaud, C., Delecluse, P., 1992a. Annual sea level variations in the southern tropical Indian Ocean from Geosat and shallow-water simulations. Journal of Geophysical Research 97, 20169-20178.

Perigaud, C., Delecluse, P., 1992b. Low-frequency sea level variations in the indian ocean from geosat altimeter and shallow-water simulations. Trends in Physical Oceanography 1, 85-110.

Perigaud, C., Delecluse, P., 1993. Interannual sea level variations in the tropical Indian Ocean from Geosat and shallow-water simulations. Journal of Physical Oceanography 23, 1916-1934.

Potemra, J. T., Luther, M. E., O'Brien, J. J., 1991. The seasonal circulation of the upper ocean in the Bay of Bengal. Journal of Geophysical Research 96, $12667-12683$. 
Rao, A. S., Behera, S. K., 2005. Subsurface influence on SST in the tropical Indian Ocean: Structure and interannual variability. Dynamics of Atmospheres and Oceans 39, 103-135.

Reverdin, G., 1987. The upper equatorial Indian Ocean: The climatological seasonal cycle. Journal of Physical Oceanography 17, 903-927.

Saji, N. H., Goswami, B. N., Vinayachandran, P. N., Yamagata, T., 1999. A dipole mode in the tropical Indian Ocean. Nature 401, 360-363.

Sakova, I. V., Meyers, G., Coleman, R., 2006. Interannual variability in the Indian Ocean using altimeter and IX1-expendable bathy- thermograph (XBT) data: Does the 18-month signal exist? Geophysical Research Letters 33, 10.1029.

Schott, F. A., McCreary, J. P., 2001. The monsoon circulation of the Indian Ocean. Progress in Oceanography 51, 1-123.

Schott, F. A., Xie, S. P., McCreary, J. P., 2009. Indian Ocean circulation and climate variability. Reviews of Geophysics 47, doi:10.1029/2007RG000245.

Shankar, D., 1998. Low-frequency variability of sea level along the coast of India. Ph.D. thesis, Goa University, Goa, India.

Shankar, D., 2000. Seasonal cycle of sea level and currents along the coast of India. Current Science 78, 279-288.

Shankar, D., Gopalakrishna, V. V., Shenoi, S. S. C., Durand, F., Shetye, S. R., Rajan, C. K., Johnson, Z., Araligidad, N., Michael, G. S., 2004. Observational evidence for westward propagation of temperature inversions in the southeastern Arabian Sea. Geophysical Research Letters 31, 1-4. 
Shankar, D., McCreary, J. P., Han, W., Shetye, S. R., 1996. Dynamics of the East India Coastal Current, 1. Analytic solutions forced by interior Ekman pumping and local alongshore winds. Journal of Geophysical Research 101, 1397513991.

Shankar, D., Shetye, S. R., 1997. On the dynamics of the Lakshadweep high and low in the southeastern Arabian Sea. Journal of Geophysical Research 102, $12551-12562$.

Shankar, D., Shetye, S. R., 1999. Are interdecadal sea level changes along the Indian coast influenced by variability of monsoon rainfall? Journal of Geophysical Research 104, 26031-26042.

Shankar, D., Shetye, S. R., 2001. Why is mean sea level along the Indian coast higher in the Bay of Bengal than in the Arabian Sea? Geophysical Research Letters 28, 563-565.

Shankar, D., Vinayachandran, P., Unnikrishnan, A. S., 2002. The monsoon currents in the north Indian Ocean. Progress in Oceanography 52, 63-120.

Shenoi, S. S. C., Shankar, D., Shetye, S. R., 1999. On the sea surface temperature high in the Lakshadweep Sea before the onset of the southwest monsoon. Journal of Geophysical Research 104, 15703-15712.

Shetye, S. R., 1993. The movement and implications of the Ganges-Bramhaputra runoff on entering the Bay of Bengal. Current Science 64, 32-38.

Shetye, S. R., Gouveia, A. D., Shankar, D., Shenoi, S. S. C., Vinayachandran, P. N., Sundar, D., Michael, G. S., Nampoothiri, G., 1996. Hydrography and 
circulation in the western Bay of Bengal during the northeast monsoon. Journal of Geophysical Research 101, 14011-14025.

Sindhu, B., Suresh, I., Unnikrishnan, A. S., Bhatkar, N. V., Neetu, S., Michael, G. S., 2007. Improved bathymetric datasets for the shallow water regions in the Indian Ocean. Journal of Earth System Science 116, 261-274.

Unnikrishnan, A. S., Kumar, S. P., Navelkar, G. S., 1997. Large-scale processes in the upper layers of the Indian Ocean inferred from temperature climatology. Journal of Marine Research 55, 93-115.

Vignudelli, S., Cipollini, P., Astraldi, M., Gasparini, G. P., Manzella, G., 2000. Integrated use of altimeter and in situ data for understanding the water exchanges between the Tyrrhenian and Ligurian seas. Journal of Geophysical Research 105, 19649-19663.

Vinayachandran, P. V., Masumoto, Y., Mikawa, T., Yamagata, T., 1999. Intrusion of the Southwest Monsoon Current into the Bay of Bengal. Journal of Geophysical Research 104, 11077-11085.

Vinayachandran, P. V., Yamagata, T., 1998. Monsoon response of the sea around Sri Lanka: Generation of thermal domes and anticyclonic vortices. Journal of Physical Oceanography 28, 1946-1960.

Volkov, D. L., 2005. Interannual variability of the altimetry-derived eddy field and surface circulation in the extra tropical north Atlantic Ocean in 1993-2001. Journal of Physical Oceanography 35, 405-426. 
Webster, P. J., Moore, A. M., Loschnigg, J. P., Leben, R. R., 1999. Coupled oceanatmosphere dynamics in the Indian Ocean during 1997-98. Nature 401, 356360.

Wyrtki, K., 1971. Oceanographic Atlas of the International Indian Ocean Expedition. National Science Foundation, Washington, D.C., 531 pp.

Xie, P., Arkin, P. A., 1999. Global precipitation: A 17-year monthly analysis based on gauge observations, satellite estimates, and numerical model outputs. Bullitein of American Meteorological Soceity 78, 2539-2558.

Yamagata, T., Behera, S. K., Luo, J. J., Masson, S., Jury, M. R., Rao, S. A., 2004. Coupled ocean-atmosphere variability in the tropical Indian Ocean. Geophysical monograph 147, 189-212.

Yu, L., O'Brien, J. J., Yang, J., 1991. On the remote forcing of the circulation in the Bay of Bengal. Journal of Geophysical Research 96, 20449-20454.

Yu, L., Xiang, B., Liu, L., Liu, N., 2005. Understanding the origins of interannual thermocline variations in the tropical Indian Ocean. Geophysical Research Letters $32,1-4$. 


\section{Figure Captions}

Figure 1: Wavelet power $\left(\mathrm{cm}^{2}\right)$, averaged over 1993-2004, based on the monthly altimeter time series. The wavelet analysis is done for each grid point and the time-averaged wavelet power, which is representative of the variability for the chosen period or frequency band, is contoured. The three panels show the wavelet power for the 3-year (top left), 17-20 month (top right), annual (bottom left), and semiannual (bottom right) periods. The dashed lines show the position of the $200 \mathrm{~m}$ isobath based on the data set of Sindhu et al. (2007). Sea-level time series and wavelet power for selected locations, marked on the top panel, are shown in Figures 3 and 4. The wavelet power scale is logarithmic with base 2. Wavelet amplitude above $9 \mathrm{~cm}^{2}$ is contoured in black at an interval of $1 \mathrm{~cm}^{2}$.

Figure 2: Longitude-period section of time-averaged wavelet power $\left(\mathrm{cm}^{2}\right)$ of altimeter sea level (top) and model sea level (bottom) along the equator. Note the minima in the CEIO at semiannual and interannual periods. The wavelet power scale is logarithmic with base 2; also plotted on a logarithmic scale is the period (ordinate). Wavelet amplitude above $6 \mathrm{~cm}^{2}$ is contoured in black at an interval of $1 \mathrm{~cm}^{2}$.

Figure 3: Low-pass-filtered sea level $(\mathrm{cm})$ for the eight locations indicated in Figures 1 and 5. Shown are altimeter sea level (thick grey curve), model MR sea level (thin black curve), and the sea level due to Solutions EQ (dotted curve) and INT (dashed curve). The three numbers at the top left corner of each panel gives the location of the station: longitude $\left({ }^{\circ} \mathrm{E}\right)$, latitude $\left({ }^{\circ} \mathrm{N}\right.$; negative for southern hemisphere), and location number in parenthesis; see Figure 1

Figure 4: Wavelet power $\left(\mathrm{cm}^{2}\right)$ of the monthly altimeter sea level at some locations. Note that the wavelet power scale is logarithmic with base 2; also 
plotted on a logarithmic scale is the period (ordinate). For the locations on a map, see Figure 1. Wavelet amplitude above $7 \mathrm{~cm}^{2}$ is contoured in black at an interval of $1 \mathrm{~cm}^{2}$. The three numbers at the top left corner of each panel gives the location of the station: longitude $\left({ }^{\circ} \mathrm{E}\right)$, latitude $\left({ }^{\circ} \mathrm{N}\right.$; negative for southern hemisphere), and location number in parenthesis; see Figure 1

Figure 5: Wavelet power $\left(\mathrm{cm}^{2}\right)$ at the 3-year period, averaged over 19932004, for the model main run (MR; top left) and Solutions EQ (top right), CST (middle left), and INT (middle right). Sea-level time series and wavelet power for selected locations, marked in all panels, are shown in Figures 3 and 9. The bottom panels show the MR response for the first (left) and second (right) baroclinic modes. Wavelet amplitude above $6 \mathrm{~cm}^{2}$ is contoured in black at an interval of 1 $\mathrm{cm}^{2}$. Note that the colour scale is different for the model wavelet in this figure and the observed wavelet in Figure 1.

Figure 6: Wavelet power $\left(\mathrm{cm}^{2} \mathrm{~s}^{-2}\right)$ of the wind forcing. Longitude-period section of time-averaged wavelet power of zonal wind along the equator and alongshore winds for the continental boundaries of the north Indian Ocean. The abscissa starts at the western boundary of the EIO and extends along the equator till the eastern boundary; it then turns counterclockwise to follow the coast of the Bay of Bengal and then the coast of the Arabian Sea till it reaches the starting point at the western boundary of the EIO. The regions marked are as follows. EQ: Equatorial IO; EB: eastern boundary of the bay; NB: northern boundary of the bay; WB: western boundary of the bay; EA: eastern boundary of the Arabian Sea; NA: northern boundary of the Arabian Sea; NWA: northwestern boundary of the Arabian Sea (coast of Oman and Gulf of Aden) till the tip at the horn of Africa; SC: Somali coast. 
Figure 7: Wavelet power $\left(\mathrm{cm}^{2} \mathrm{~s}^{-2}\right)$ at the annual (top left), 17-20 month (top right), 3-year (bottom left), and 10-year (bottom right) periods for Ekman pumping. The NCEP wind data for 1958-2004 were used for the wavelet analysis. Wavelet amplitude above $10 \mathrm{~cm}^{2} \mathrm{~s}^{-2}$ is contoured in black at an interval of 2 $\mathrm{cm}^{2} \mathrm{~s}^{-} 2$.

Figure 8: Wavelet power $\left(\mathrm{cm}^{2}\right)$ for the model sea level at annual (top left), 17-20 month (top right), 3-year (middle left), and 10-year (middle right) periods. The wavelet power for Solutions EQ (bottom left) and INT (bottom right) are also shown for the 10-year period. All these wavelet power spectra were estimated using the model response for 1958-2004. Wavelet amplitude above $9 \mathrm{~cm}^{2}$ is contoured in black at an interval of $1 \mathrm{~cm}^{2}$.

Figure 9 Wavelet power $\left(\mathrm{cm}^{2}\right)$ of the low-pass-filtered model sea level at some locations. Note that the wavelet power scale is logarithmic with base 2; also plotted on a logarithmic scale is the period (ordinate). For the locations on a map, see Figure 5. Wavelet amplitude above $6 \mathrm{~cm}^{2}$ is contoured in black at an interval of $1 \mathrm{~cm}^{2}$.The three numbers at the top left corner of each panel gives the location of the station: longitude $\left({ }^{\circ} \mathrm{E}\right)$, latitude $\left({ }^{\circ} \mathrm{N}\right.$; negative for southern hemisphere), and location number in parenthesis; see Figure 1.

Figure 10: Streamfunction $\left[\psi\left(\mathrm{cm}^{2} \mathrm{~s}^{-1}\right)\right.$; top left $]$, sea level $[d(\mathrm{~cm})$; top right], and absolute value of sea level ( $|d|$; bottom left) are shown for the analytic solution with India represented by a strip north of $6^{\circ} \mathrm{N}$ at $75^{\circ} \mathrm{E}$. The solution (sea level $d$ ) without the India strip is also shown (bottom right). The absolute value $(|d|)$ is an analog of the interannual-sea-level-variability in the numerical solution and the pattern can be compared with that of the wavelet analysis.

Figure 11: Wavelet power $\left(\mathrm{cm}^{2}\right)$ at the 3-year period for the sea level response 
in the numerical model forced by the idealized wind field given by Equation (16). The top panels show the wavelet power for a rectangular basin, as in the analytic model, with India (left) and without India (right). The bottom panels show the response for a realistic basin geometry (as in Figure 5). The bottom left panel shows the response to a zonally invariant $\tau_{0}$, as in the analytic model (Figure 10) or for the simulations with the rectangular basin (top panels). The bottom right panel shows the response to a $\tau_{0}$ that was restricted to the CEIO. For this simulation, $\tau_{0}$ was constant in $75-90^{\circ} \mathrm{E}$ and was tapered nonlinearly to zero at $40^{\circ} \mathrm{E}$ and $100^{\circ} \mathrm{E}$. 


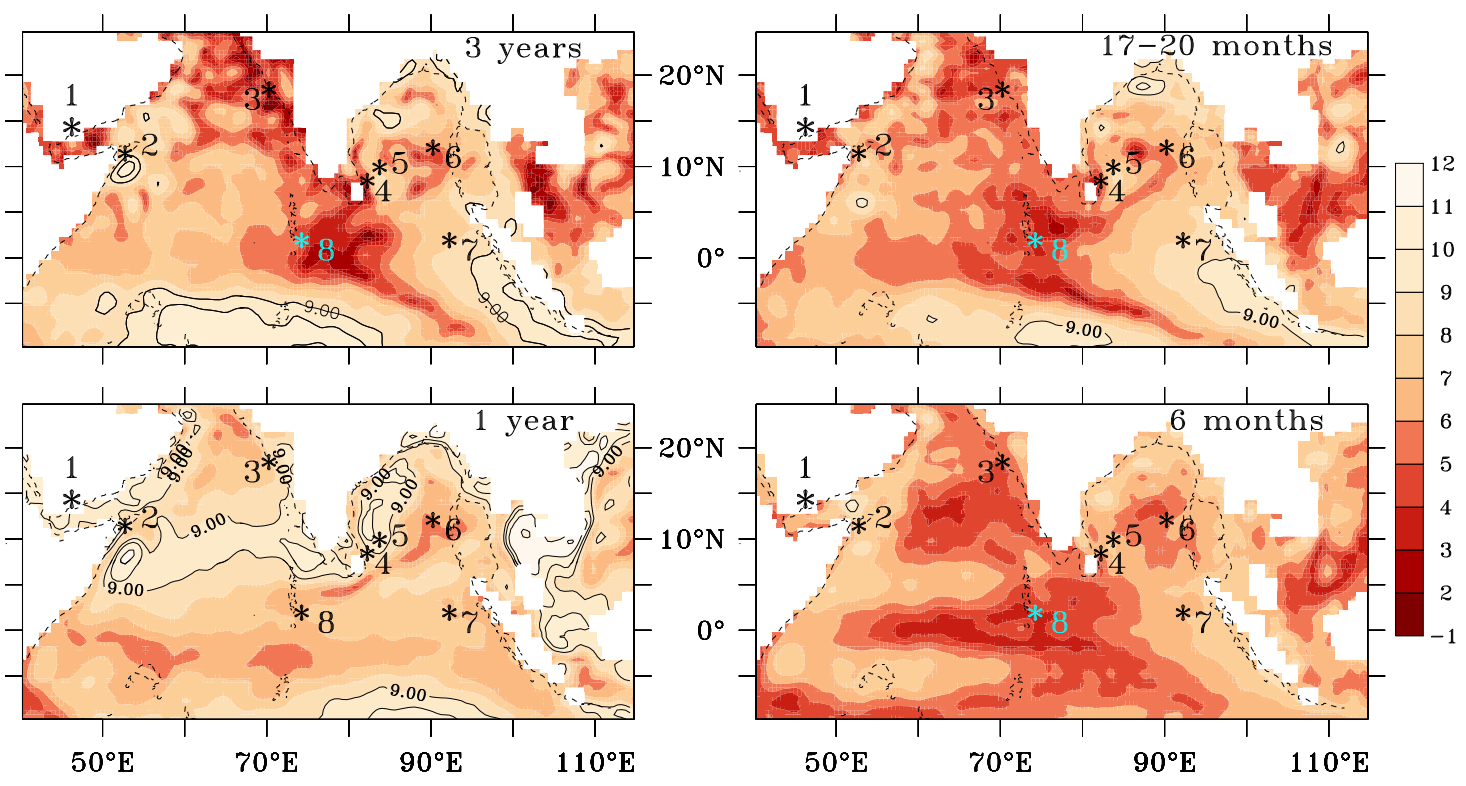

Figure 1: . 


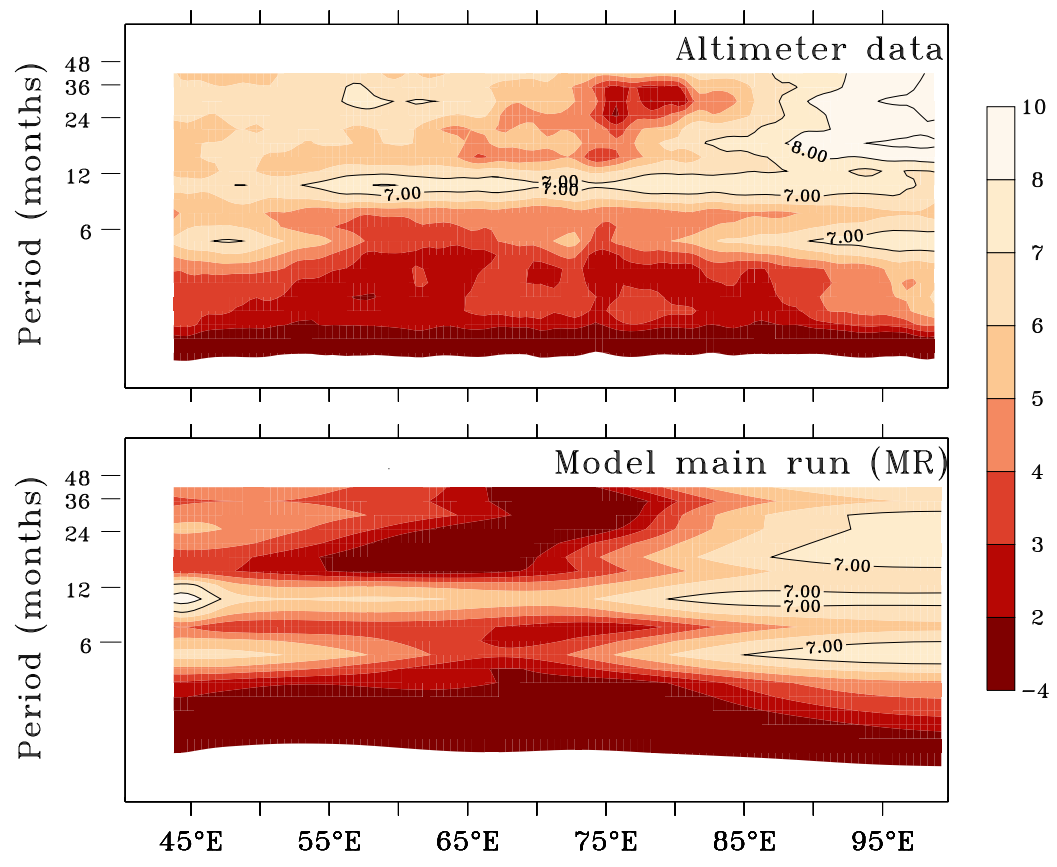

Figure 2: . 

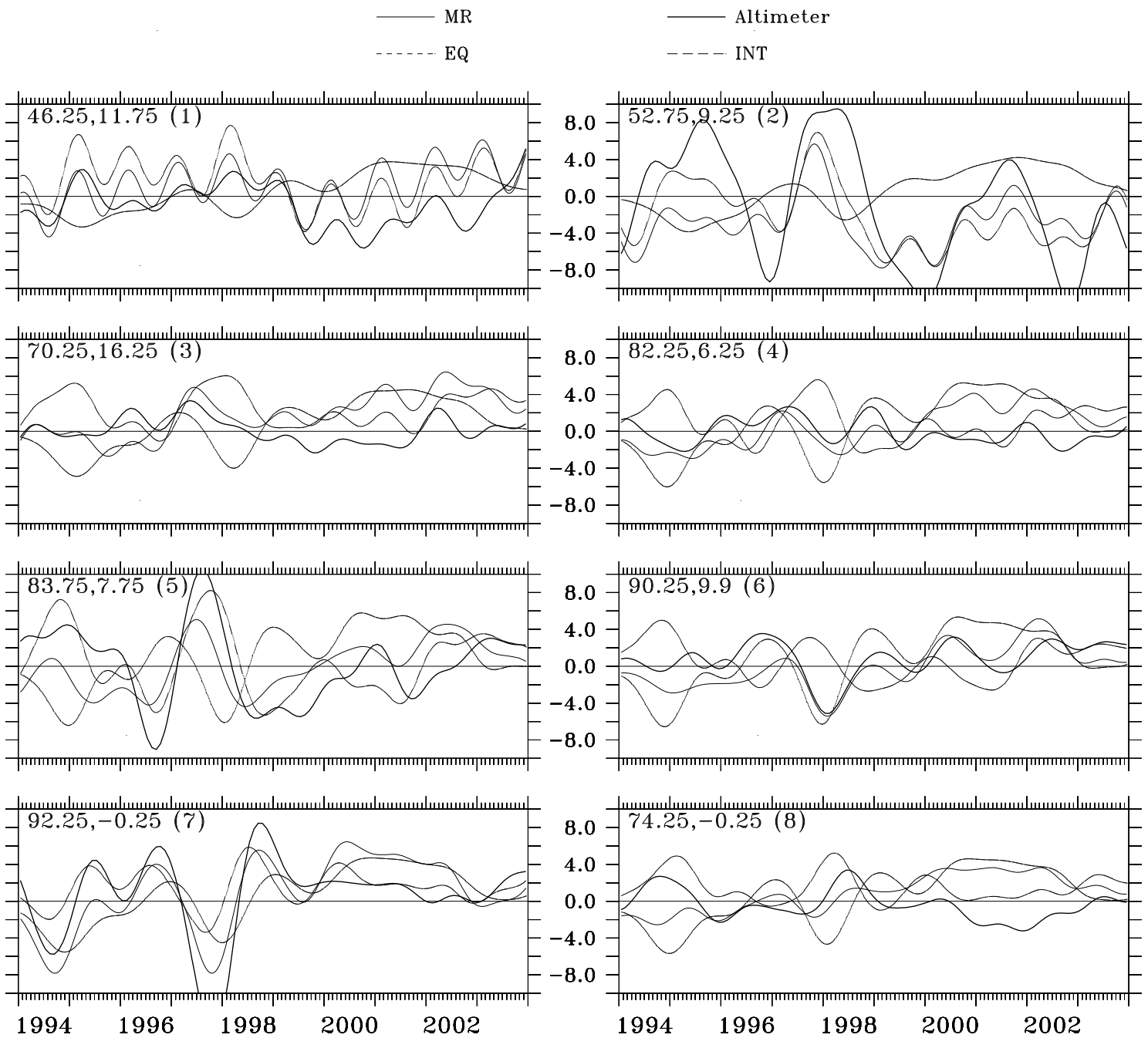

Figure 3: 

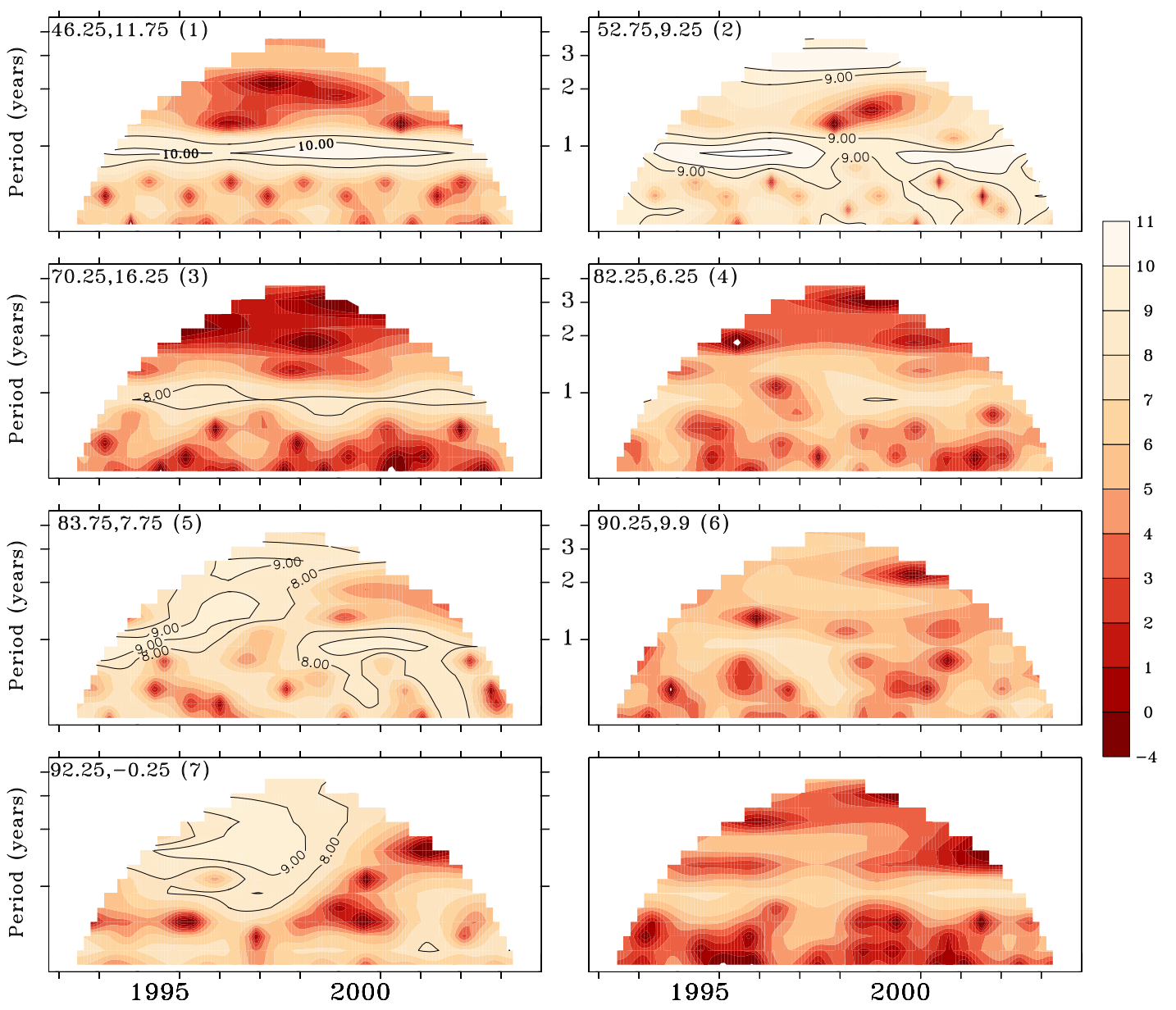

Figure 4: . 


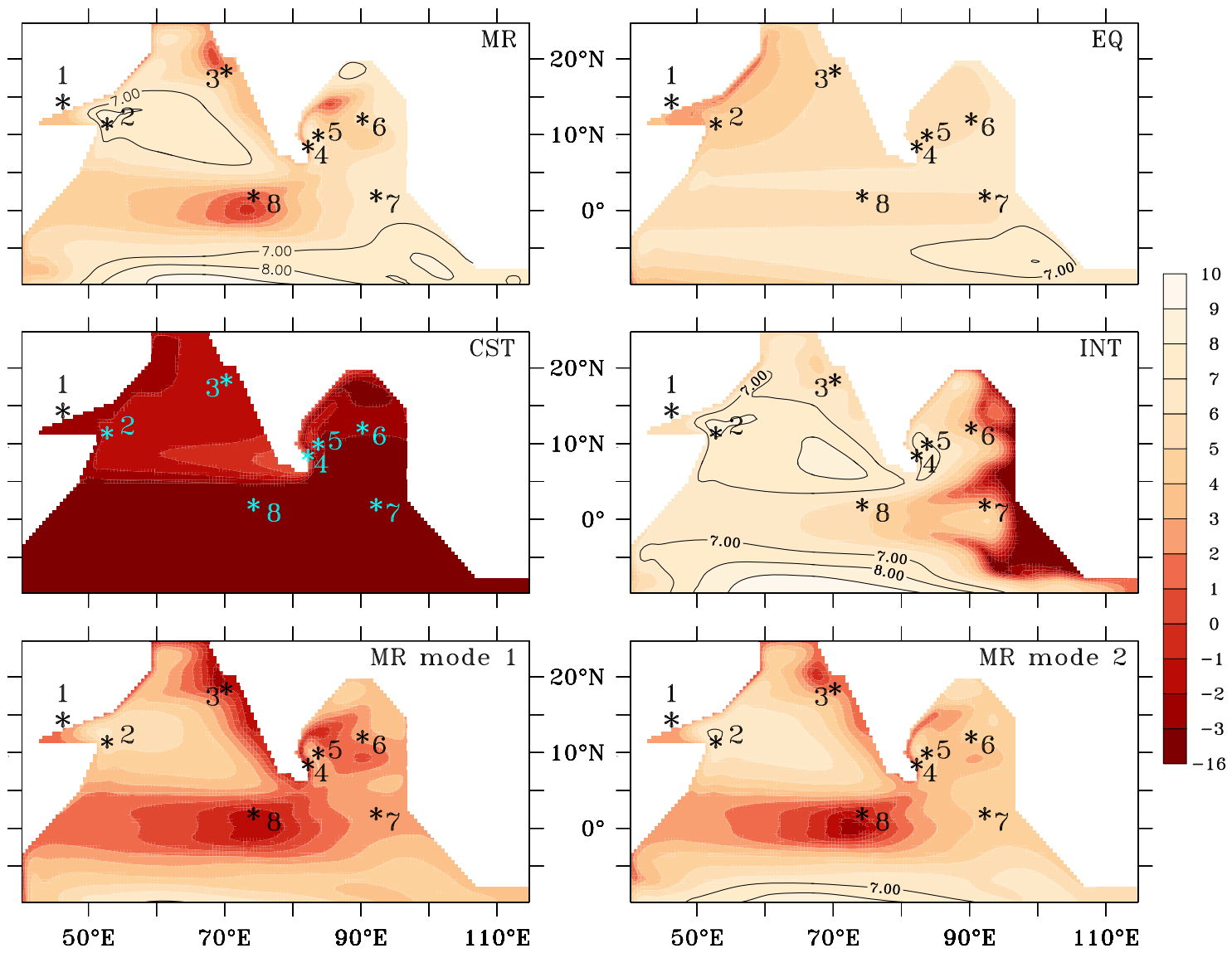

Figure 5: . 


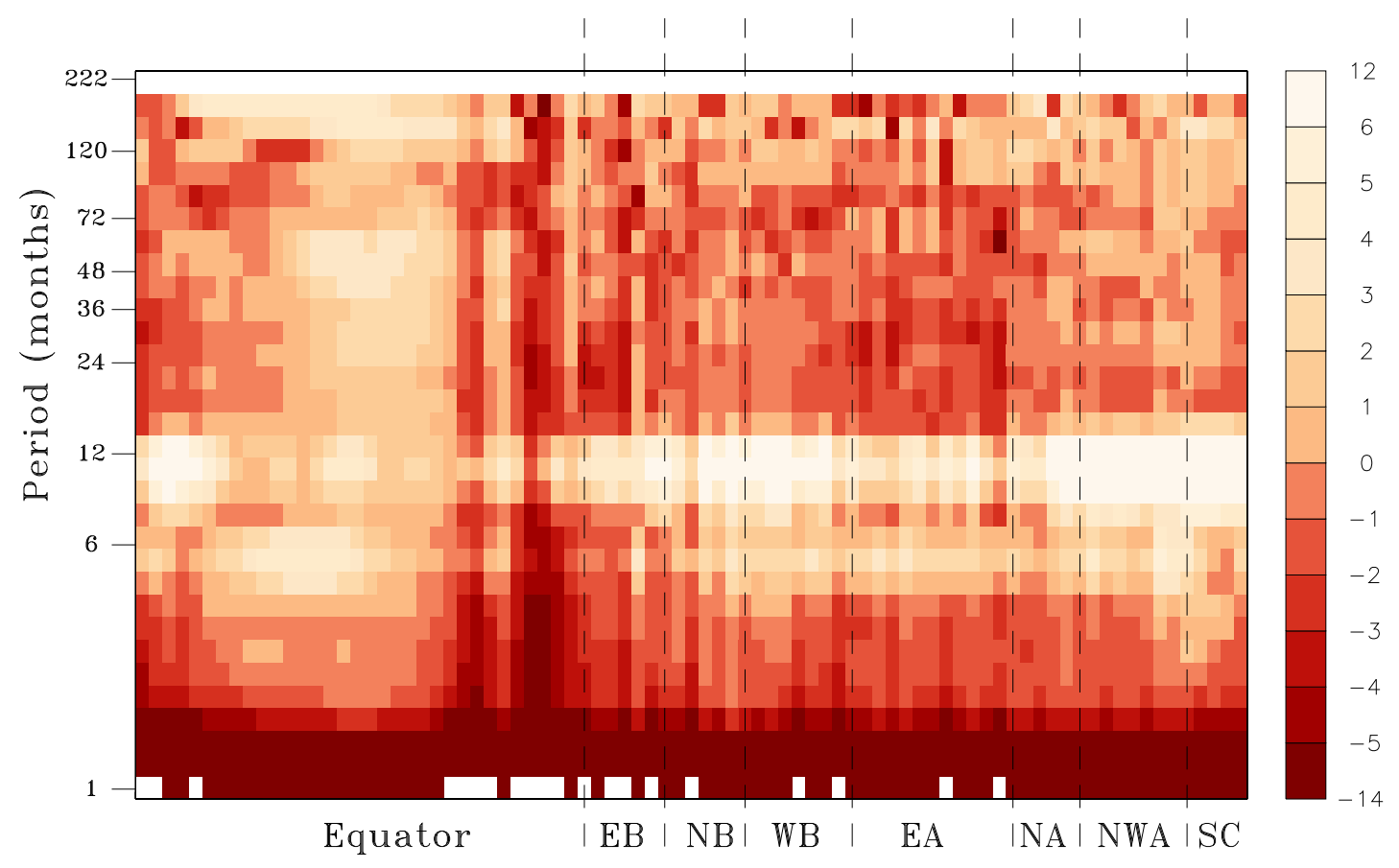

Figure 6: . 


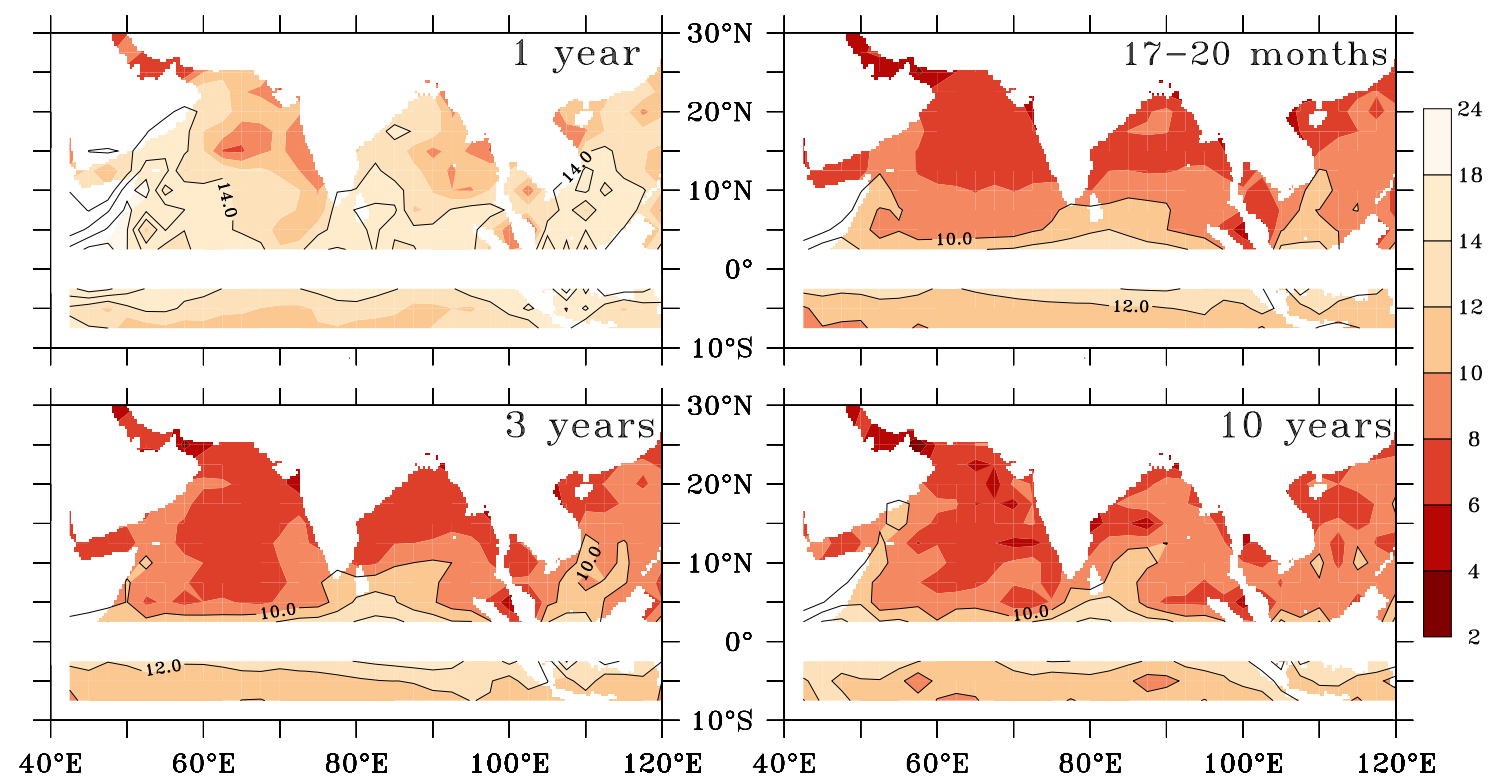

Figure 7: . 


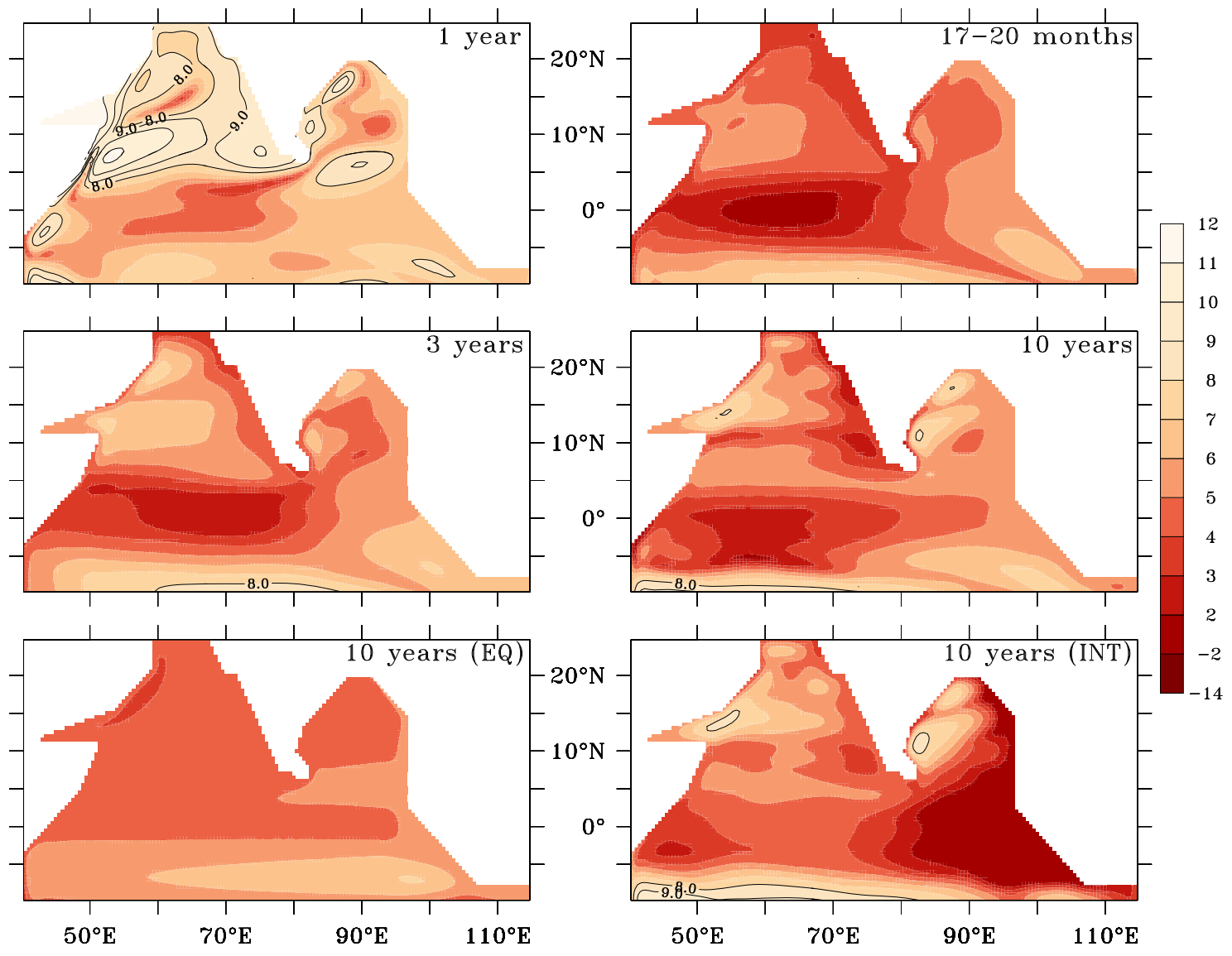

Figure 8: . 

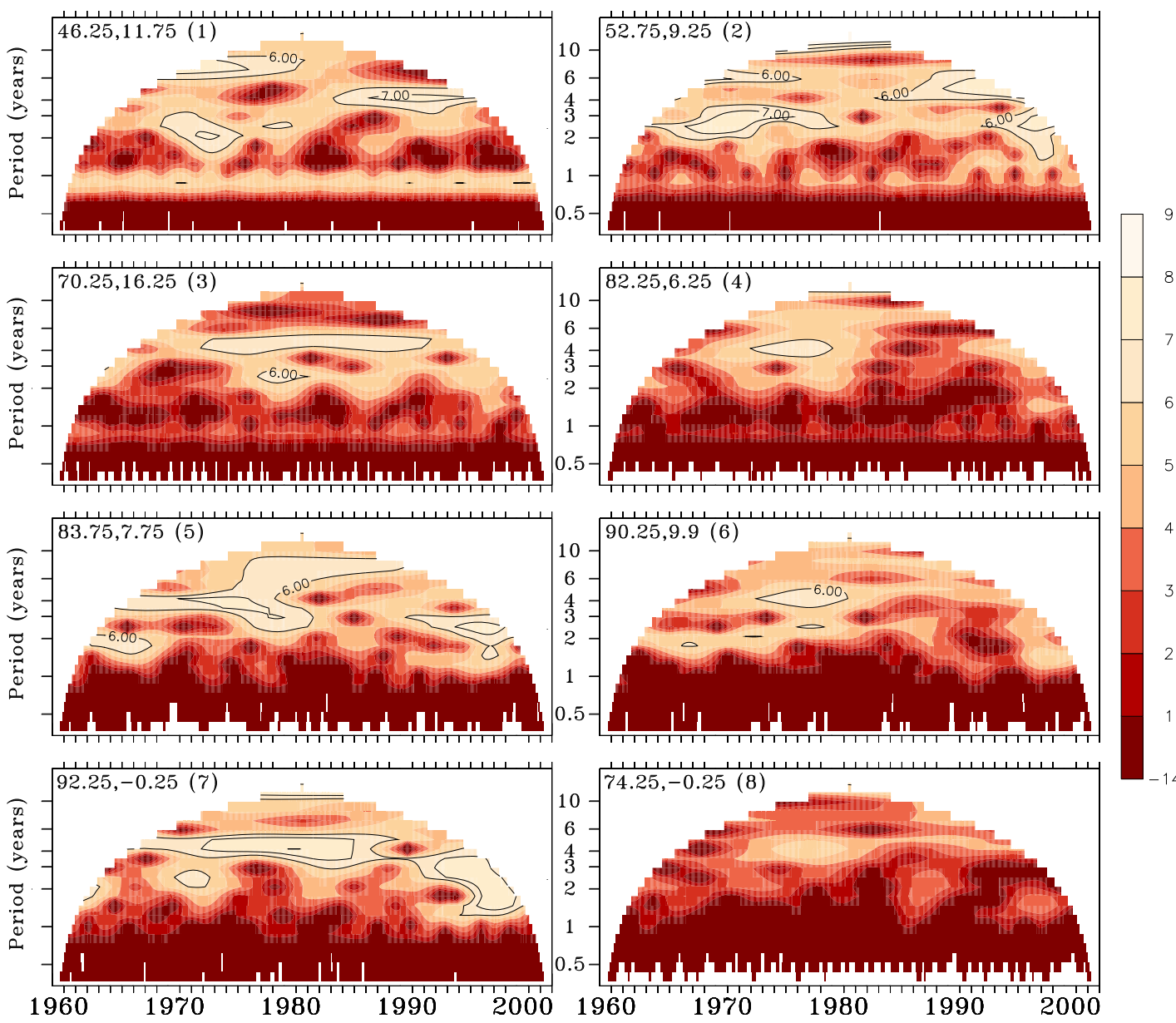

Figure 9: . 

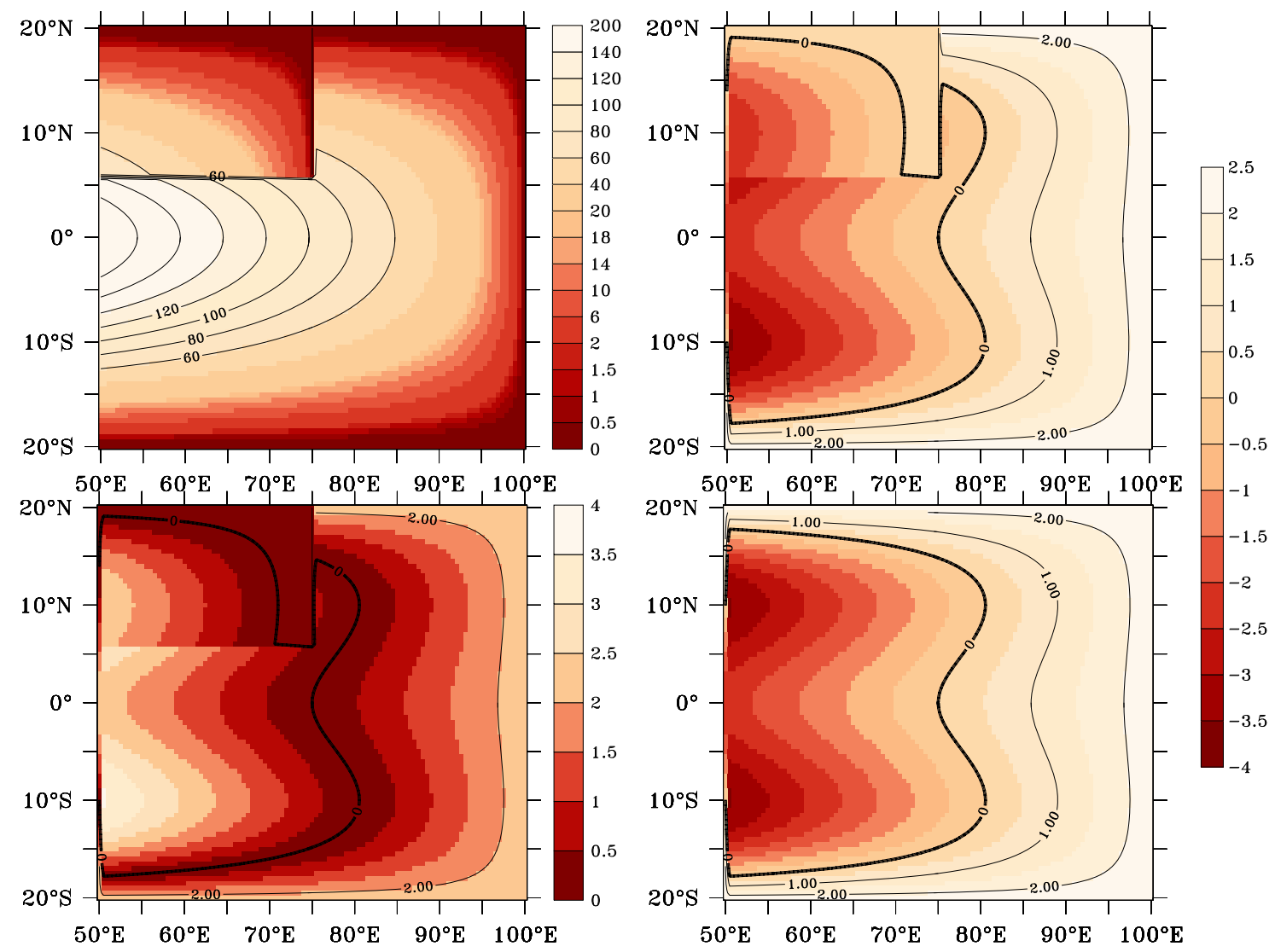

Figure 10: . 


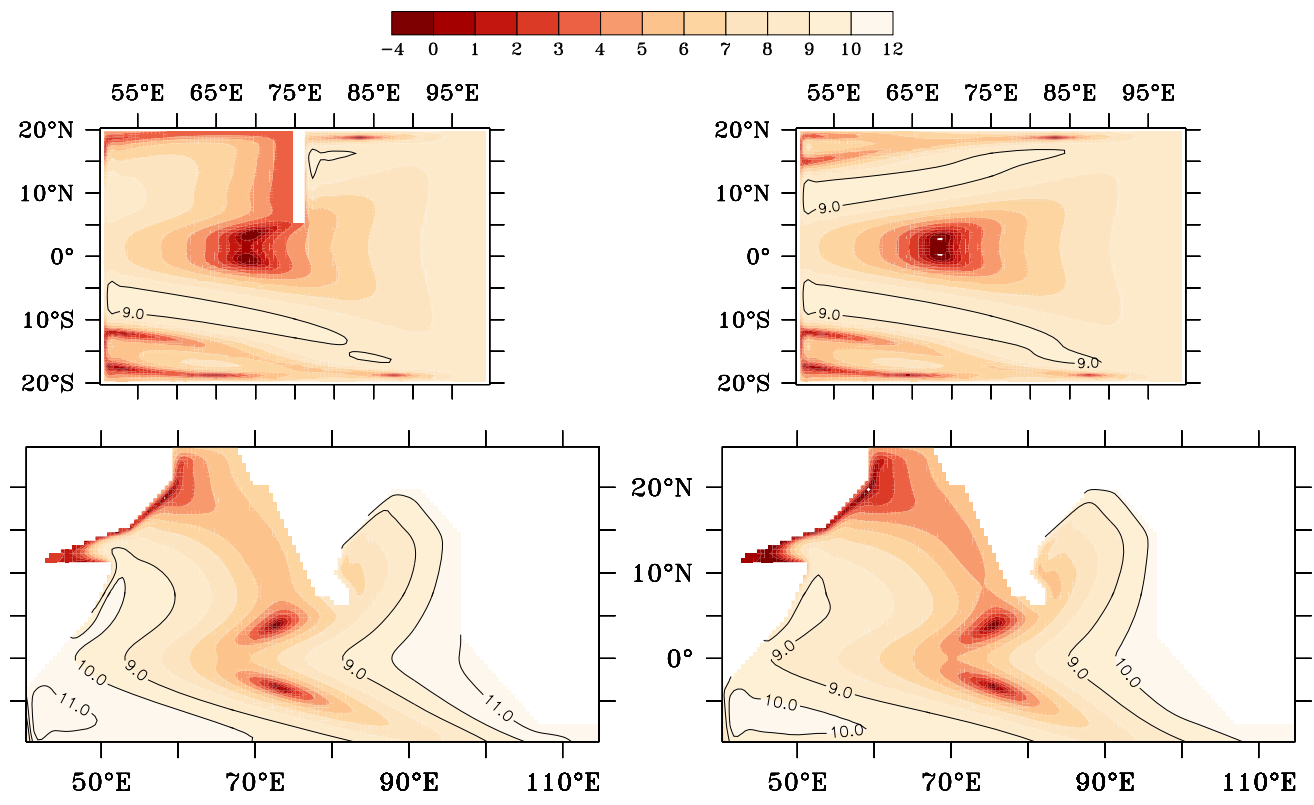

Figure 11: . 